\title{
The CAMS volcanic forecasting system utilizing near-real time data assimilation of S5P/TROPOMI $\mathrm{SO}_{2}$ retrievals
}

Antje Inness ${ }^{1}$, Melanie Ades ${ }^{1}$, Dimitris Balis ${ }^{3}$, Dmitry Efremenko ${ }^{2}$, Johannes Flemming ${ }^{1}$, Pascal Hedelt $^{2}$, Maria-Elissavet Koukouli ${ }^{3}$, Diego Loyola ${ }^{2}$, and Roberto Ribas ${ }^{1}$

5 'European Centre for Medium-Range Weather Forecasts (ECMWF), Shinfield Park, Reading, RG2 9AX, UK.

${ }^{2}$ Deutsches Zentrum für Luft und Raumfahrt (DLR), Institut für Methodik der Fernerkundung (IMF), Oberpfaffenhofen, Germany.

${ }^{3}$ Laboratory of Atmospheric Physics, Aristotle University of Thessaloniki, Greece

Correspondence to: Antje Inness (antje.inness@ecmwf.int)

10 Abstract.

The Copernicus Atmosphere Monitoring Service (CAMS), operated by the European Centre for Medium-Range Weather Forecasts on behalf of the European Commission, provides daily analyses and 5-day forecasts of atmospheric composition, including forecasts of volcanic sulphur dioxide $\left(\mathrm{SO}_{2}\right)$ in near-real time. CAMS currently assimilates total column $\mathrm{SO}_{2}$ retrievals from the GOME-2 instruments on MetOp-B and -C and the TROPOMI instrument on Sentinel-5P which give

15 information about the location and strength of volcanic plumes. However, the operational TROPOMI and GOME-2 retrievals do not provide any information about the height of the volcanic plumes and therefore some prior assumptions need to be made in the CAMS data assimilation system about where to place the resulting $\mathrm{SO}_{2}$ increments in the vertical. In the current operational CAMS configuration, the $\mathrm{SO}_{2}$ increments are placed in the mid-troposphere, around $550 \mathrm{hPa}$ or $5 \mathrm{~km}$. While this gives good results for the majority of volcanic emissions, it will clearly be wrong for eruptions that inject $\mathrm{SO}_{2}$ at very different altitudes, in particular exceptional events where part of the $\mathrm{SO}_{2}$ plume reaches the stratosphere.

A new algorithm, developed by DLR for GOME-2 and TROPOMI and optimized in the frame of the ESA-funded Sentinel5P Innovation- $\mathrm{SO}_{2}$ Layer Height Project, the Full-Physics Inverse Learning Machine (FP_ILM) algorithm, retrieves $\mathrm{SO}_{2}$ layer height from TROPOMI in NRT in addition to the $\mathrm{SO}_{2}$ column. CAMS is testing the assimilation of these data, making use of the NRT layer height information to place the $\mathrm{SO}_{2}$ increments at a retrieved altitude. Assimilation tests with the TROPOMI SO $\mathrm{SO}_{2}$ layer height data for the Raikoke eruption in June 2019 show that the resulting $\mathrm{CAMS} \mathrm{SO}_{2}$ plume heights agree better with IASI plume height retrievals than operational CAMS runs without the TROPOMI $\mathrm{SO}_{2}$ layer height information and that making use of the additional layer height information leads to improved $\mathrm{SO}_{2}$ forecasts than when using the operational CAMS configuration. By assimilating the $\mathrm{SO}_{2}$ layer height data the CAMS system can predict the overall location of the Raikoke $\mathrm{SO}_{2}$ plume up to 5 days in advance for about 20 days after the initial eruption.

\section{Introduction}

Volcanoes can cause serious disruptions for society, not just for people living near them, but also further afield when ash and sulphur dioxide $\left(\mathrm{SO}_{2}\right)$ emitting from highly explosive eruptions reach the upper troposphere or stratosphere, above the clouds, and therefore are transported over vast distances by the prevailing winds. Ash and $\mathrm{SO}_{2}$ are a serious concern for the aviation industry, reducing visibility and in severe cases can lead to engine failure or cause permanent damage to aircraft engines (Prata et al., 2019). The immediate danger to the aircraft comes mainly from the emitted ash, although $\mathrm{SO}_{2}$ is also an aviation hazard, potentially causing long-term damage via corrosion and sulfidation of the engines (Schmidt et al., 2014). In the short-term, $\mathrm{SO}_{2}$ in the aircraft cabin is the biggest issue leading to respiratory problems for passengers and crew. Planes 
therefore try to avoid volcanic plumes and after the 2010 eruption of the Icelandic Eyjafjallajökull volcano (e.g. Stohl et al., 2011; Dacre et al., 2011; Thomas and Prata, 2011) European air traffic was grounded for several days. Forecasts of the location and the altitude of volcanic $\mathrm{SO}_{2}$ or ash plumes can therefore provide important information for the aviation industry. Satellite retrievals of volcanic ash and $\mathrm{SO}_{2}$ can help to track volcanic plumes, as done by the Support to Aviation Control Service (sacs.aeronomie.be; Brenot et al., 2014) and the EUNADICS (European Natural Airborne Disaster Information and Coordination System for Aviation) prototype Early Warning System (Brenot et al., 2021). These services, as well as plume dispersion modelling (e.g. de Leeuw et al., 2020; Harvey and Dacre, 2016), are used by the Volcanic Ash Advisory Centres (VAACs) to advise civil aviation authorities in case of volcanic eruptions. While $\mathrm{SO}_{2}$ is often used as a proxy for ash, the $\mathrm{SO}_{2}$ and ash plumes can be located at different altitudes and be transported in different directions as was the case for the Icelandic Grímsvötn eruption in 2011 (Moxnes et al., 2013, Prata et al., 2017).

The Copernicus Atmosphere Monitoring Service (CAMS), operated by the European Centre for Medium-Range Weather Forecasts (ECMWF) on behalf of the European Commission, provides daily analyses and 5-day forecasts of atmospheric composition, including forecasts of volcanic $\mathrm{SO}_{2}$ in near-real time (NRT). However, the assimilation and forecasting of volcanic $\mathrm{SO}_{2}$ plumes in NRT is difficult. Since the CAMS forecast system runs within 3 hours of the observations being taken, information about volcanic $\mathrm{SO}_{2}$ emission strength and the altitude of $\mathrm{SO}_{2}$ plumes is usually not available, with only the total column-integrated $\mathrm{SO}_{2}$ amount $\left(\mathrm{TCSO}_{2}\right)$ able to be provided to adjust the model's predictions. CAMS assimilates near-real-time $\mathrm{TCSO}_{2}$ using the method described in Flemming and Inness (2013) in its operational NRT system to routinely assimilate $\mathrm{TCSO}_{2}$ retrievals from the Global Ozone Monitoring Experiment-2 (GOME-2) instruments produced 60 by Eumetsat's Satellite Application Facility on Atmospheric Composition Monitoring (ACSAF) and from the Sentinel-5P Tropospheric Monitoring Instrument (TROPOMI) provided by the European Space Agency (ESA). Both are using retrievals developed by the German Aerospace Centre (DLR) which give information about the emitted volcanic $\mathrm{SO}_{2}$ and their horizontal location in NRT but do not provide any information about the altitudes of the volcanic plumes. Prior assumptions therefore need to be made in the CAMS data assimilation system about where in the vertical the resulting $\mathrm{SO}_{2}$ increments

65 should be placed. In the absence of NRT height information, the default is to place the $\mathrm{SO}_{2}$ increments in the midtroposphere, around $550 \mathrm{hPa}$ or $5 \mathrm{~km}$. Although clearly a simplified approach, the method is a reasonable approximation to the real situation, using the data assimilation procedure as a mid-tropospheric $\mathrm{SO}_{2}$ source in areas of elevated volcanic $\mathrm{TCSO}_{2}$. The $\mathrm{SO}_{2}$ analysis field will then be transported by the model's prevailing winds and thereby result in quite realistic volcanic $\mathrm{SO}_{2}$ plumes. While this method produces good results for a large number of volcanic eruptions that inject $\mathrm{SO}_{2}$ into the mid-troposphere, it will clearly be wrong for eruptions that inject $\mathrm{SO}_{2}$ at very different altitudes, in particular for the most explosive events where part of the $\mathrm{SO}_{2}$ reaches the stratosphere. In those cases, the CAMS system will not be able to forecast the $\mathrm{SO}_{2}$ transport well, because the model $\mathrm{SO}_{2}$ plume will be located at the wrong altitude where the prevailing winds might transport the $\mathrm{SO}_{2}$ in the wrong direction or height. The availability and use of NRT information about the altitude of the

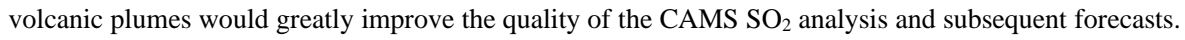

75

For hindcasts of volcanic eruptions with a system that does not run in NRT it is easier to make use of better injection height information. In this case, observations about injection height and emission strength might be available. Furthermore, CAMS can run an ensemble of $\mathrm{SO}_{2}$ tracers emitted at different altitudes and determine the best altitude and emission strength from comparisons of the resulting model fields with the available $\mathrm{TCSO}_{2}$ observations, using a method described in Flemming and

80 Inness (2013). The parameters (plume height and emission flux) derived in this way can subsequently be used to provide a volcanic $\mathrm{SO}_{2}$ source term in the CAMS forecast model and can also be used in the data assimilation system to modify the $\mathrm{SO}_{2}$ background error standard deviation to peak at the corresponding model level. However, this is not possible in NRT. 
A new algorithm, developed by DLR for GOME-2 and adapted to TROPOMI, which is currently being optimized in the 85 frame of the ESA-funded Sentinel-5P (S5P) Innovation-SO $\mathrm{SO}_{2}$ Layer Height Project (S5P+I: $\mathrm{SO}_{2} \mathrm{LH}$ ), the Full-Physics Inverse Learning Machine (FP_ILM) algorithm (Hedelt et al., 2019), retrieves $\mathrm{SO}_{2}$ layer height (LH) information from TROPOMI in NRT in addition to the $\mathrm{SO}_{2}$ column. This is different from the operational ESA NRT TROPOMI retrieval which does not provide plume height information. CAMS is testing the assimilation of the FP_ILM data, making use of the NRT LH information. In this paper we document the current use of the operational $\mathrm{TCSO}_{2}$ data in the CAMS data assimilation

90 system, present results from assimilation tests with the FP_ILM TROPOMI $\mathrm{SO}_{2} \mathrm{LH}$ data for the eruption of the Raikoke volcano in June 2019 and show that making use of the NRT LH information leads to improved $\mathrm{SO}_{2}$ analyses and in particular $\mathrm{SO}_{2}$ forecasts.

This paper is structured in the following way. Section 2 describes the $\mathrm{SO}_{2}$ datasets used in this study and Section 3 describes the CAMS model and $\mathrm{SO}_{2}$ data assimilation setup. Section 4 presents the results from the assimilation of TROPOMI data for eruption of Raikoke in June 2019, including sensitivity studies to evaluate choices made for the $\mathrm{SO}_{2}$ background errors, and evaluates the quality of the resulting $\mathrm{SO}_{2}$ analyses and forecasts with and without $\mathrm{LH}$ information. Section 5 presents the conclusions.

\section{Datasets}

100 The $\mathrm{SO}_{2}$ satellite data currently used in the CAMS NRT system are the operational $\mathrm{TCSO}_{2}$ retrievals from TROPOMI on S5P produced by ESA and from the GOME-2 instruments on MetOp-B and MetOp-C produced by Eumetsat's ACSAF. These retrievals come with a volcanic flag, i.e. the data producers mark the pixels that are affected by volcanic $\mathrm{SO}_{2}$, and only pixels that are flagged as volcanic are assimilated in the CAMS system. Using TROPOMI in addition to GOME-2 has two advantages: (1) TROPOMI has better spatial coverage and a lower detection limit than GOME-2 and (2) because TROPOMI

105 has a different overpass time (9.30 UTC for MetOp, 13.30 UTC for S5P) using both instruments improves the chances of having an overpass over a volcano when an eruption happens or shortly afterwards.

\subsection{NRT TROPOMI TCSO 2 retrieval}

TROPOMI on board the S5P satellite provides high-resolution spectral measurements in the ultraviolet (UV), visible (Vis), near infrared and shortwave-infrared parts of the spectrum, allowing several atmospheric trace gases to be retrieved,

110 including $\mathrm{SO}_{2}$ from the UV-Vis part of the spectrum. The horizontal resolution of TROPOMI for the UV-Vis is $5.5 \mathrm{~km} \times 3.5$ $\mathrm{km}(7 \mathrm{~km} \times 3.5 \mathrm{~km}$ before 6 August 2019) with daily global coverage. The theoretical baseline for the operational TROPOMI $\mathrm{SO}_{2}$ retrieval is described in Theys et al. (2017) and further information can be found in Algorithm Theoretical Basis Document (ATBD), Product User Manual (PUM) and readme files available from the TROPOMI website (http://www.tropomi.eu/documents/). The atmospheric $\mathrm{SO}_{2}$ vertical column density is retrieved in three fitting windows

115 (312-326 nm, 325-335 nm and 360-390 nm) using a Differential Optical Absorption Spectroscopy (DOAS) method (Platt and Stutz, 2008; Platt, 2017), in which the slant $\mathrm{SO}_{2}$ column is retrieved and converted into vertical columns by using air mass factors. The log-ratio of the observed UV-visible spectrum of radiation backscattered from the atmosphere and an observed reference spectrum are used to derive a slant column density, which represents the $\mathrm{SO}_{2}$ concentration integrated along the mean light path through the atmosphere. This is performed by fitting $\mathrm{SO}_{2}$ absorption cross-sections to the measured reflectance in a given spectral interval. In a second step, slant columns are corrected for possible biases. Finally, the slant columns are converted into vertical columns by means of air mass factors obtained from radiative transfer calculations, accounting for the viewing geometry, clouds, surface properties and prior $\mathrm{SO}_{2}$ vertical profile shapes. A volcano activity detection algorithm going back to Brenot et al. (2014) is used to identify elevated $\mathrm{SO}_{2}$ values from volcanic 

(enhanced $\mathrm{SO}_{2}$ detection in vicinity of known volcano). Furthermore, only TROPOMI $\mathrm{SO}_{2}$ pixels with values greater than 5 DU are assimilated in the operational CAMS system to avoid assimilating $\mathrm{SO}_{2}$ from outgassing volcanoes which are covered by $\mathrm{SO}_{2}$ emissions in the CAMS model. The TROPOMI $\mathrm{SO}_{2}$ data are averaged to the model resolution (TL511, about 40km) before being used in the CAMS system.

\begin{tabular}{|l|l|}
\hline Flag value & Description \\
\hline 0 & No detection \\
\hline 1 & Enhanced $\mathrm{SO}_{2}$ detection \\
\hline 2 & Enhanced $\mathrm{SO}_{2}$ detection in vicinity of known volcano \\
\hline 3 & Enhanced $\mathrm{SO}_{2}$ in vicinity of anthropogenic source \\
\hline 4 & Enhanced $\mathrm{SO}_{2}$ in $\mathrm{SAA}$ or for $\mathrm{SZA}>70^{\circ}$ \\
\hline
\end{tabular}

Table 1: Volcanic $\mathrm{SO}_{2}$ flags implemented in TROPOMI $\mathrm{SO}_{2}$ retrieval. The same flags are also used for $\mathrm{TROPOMI}_{\mathrm{SO}} \mathrm{LH}$ data and GOME-2C GPD4.9 $\mathrm{SO}_{2}$ data.

\subsection{FP_ILM NRT TROPOMI Layer Height retrieval}

2.3 NRT GOME-2 $\mathrm{TCSO}_{2}$ retrieval

150 GOME-2 (Munro et al., 2016) on board the MetOp-A, -B and -C satellites measures in the UV and Vis part of the spectrum $(240-790 \mathrm{~nm})$. MetOp-B and -C have a swath of $1920 \mathrm{~km}$ at $40 \mathrm{~km} \mathrm{x} 80 \mathrm{~km}$ ground pixel resolution, while MetOp-A has a narrower swath of $960 \mathrm{~km}$ at $40 \mathrm{~km}$ x $40 \mathrm{~km}$. Global coverage with GOME-2 is achieved within 1.5 days. The GOME-2 measurements allow for the retrieval of ozone and a range of atmospheric trace gases, including $\mathrm{SO}_{2}$ which is retrieved with the GOME Data Processor (GDP) developed by DRL that uses a DOAS method. GDP4.8 is used for GOME-2A and

155 GOME-2B (with a fitting window from 315-326 nm) and GDP4.9 for GOME-2C (with a fitting window of 312-326 nm to include the strong $\mathrm{SO}_{2}$ line at $313 \mathrm{~nm}$ ). Input parameters for the DOAS fit include the absorption cross section of $\mathrm{SO}_{2}$ and the absorption cross sections of interfering gases, ozone and $\mathrm{NO}_{2}$, and a correction is made in the DOAS fit to account for the ring effect (rotational Raman scattering). An empirical interference correction is applied to the $\mathrm{SO}_{2}$ slant column values 
to reduce the interference from ozone absorption (Rix et al., 2012). To reduce the interference from ozone absorption, the retrieval includes the fitting of two pseudo ozone cross-sections following the approach of Pukite et al. (2010). As in the case for the TROPOMI dataset, a volcano activity detection algorithm is used to identify elevated $\mathrm{SO}_{2}$ values from volcanic eruptions. Such flags were implemented in GDP4.8 (see Table 2) and further improved in GDP4.9 to use the same flagging as for TROPOMI (see Table 1). CAMS only assimilates the GOME-2 $\mathrm{SO}_{2}$ data that are flagged as volcanic (value=1 for GDP4.8; value=1 or 2 for GDP4.9) and assimilates GOME-2B and GOME-2C in the NRT system operational in 2021. In this paper only $\mathrm{SO}_{2}$ data from GOME-2B are used.

\begin{tabular}{|l|l|}
\hline Flag value & Description \\
\hline 0 & No detection \\
\hline 1 & Elevated $\mathrm{SO}_{2}$ value due to a volcanic $\mathrm{SO}_{2}$ plume \\
\hline 2 & $\begin{array}{l}\text { Elevated } \mathrm{SO}_{2} \text { value in a region with known increased } \\
\text { background level (either anthropogenic pollution or SAA region) }\end{array}$ \\
\hline
\end{tabular}

Table 2: Volcanic $\mathrm{SO}_{2}$ flags implemented in GDP4.8 used for GOME-2A and -2B $\mathrm{SO}_{2}$ retrievals.

\subsection{IASI $\mathrm{SO}_{2}$ plume altitude retrieval}

170 The Infrared Atmospheric Sounding Instrument (IASI) is flying on board of EUMETSAT's MetOp-A (since 2006), MetOpB (since 2012) and MetOp-C (since 2017) satellite platforms (Clerbaux et al., 2015). The instruments measure the upwelling radiances in the thermal infrared spectral range extending from 645 to $2760 \mathrm{~cm}^{-1}$, with high radiometric quality, $0.5 \mathrm{~cm}^{-1}$ spectral resolution. A total of 120 views are collected over a swath of $\sim 2200 \mathrm{~km}$ using a stare-and-stay mode of 30 arrays of 4 individual elliptical pixels, each of which is $12 \mathrm{~km}$ diameter at nadir, increasing at the larger viewing angles. IASI provides global monitoring of total ozone, carbon monoxide, methane, ammonia, nitric acid and $\mathrm{SO}_{2}$, among others atmospheric constituents.

The IASI/MetOp $\mathrm{SO}_{2}$ columnar data are operationally provided by the EUMETSAT's ACSAF. In Clarisse et al. (2012) a novel algorithm for the sounding of volcanic $\mathrm{SO}_{2}$ plumes above $\sim 5 \mathrm{~km}$ altitude was presented and applied to IASI observations. The algorithm is able to view a wide variety of total column ranges (from 0.5 to 5000 D.U.), exhibits a low theoretical uncertainty (3-5\%) and near real time applicability which was demonstrated for the recent eruptions of Sarychev in Russia, Kasatochi in Alaska, Grimsvötn in Iceland, Puyehue-Cordon Caulle in Chile and Nabro in Eritrea (Tournigand et al., 2020.) A validation of this algorithm on the Nabro eruption observations using forward trajectories and CALIOP/CALIPSO space-born lidar coincident measurements is presented in Clarisse et al. (2014) where the expansion of

185 the algorithm to also provide $\mathrm{SO}_{2}$ plume altitudes is further described. The IASI/MetOp $\mathrm{SO}_{2} \mathrm{ACSAF}$ product includes five $\mathrm{SO}_{2}$ column data at assumed layer heights of 7,10,13,16 and $25 \mathrm{~km}$, as well as a retrieved best estimate for the $\mathrm{SO}_{2}$ plume altitude and associated $\mathrm{SO}_{2}$ column. Note that the $\mathrm{SO}_{2}$ plume altitudes provided by this algorithm are quantized every $0.5 \mathrm{~km}$. This dataset is publicly available from https://iasi.aeris-data.fr/ $/ \mathrm{SO}_{2} \_$iasi_a $\operatorname{arch} /$.

190 For the requirements of the validation against the CAMS experiments, all available IASI $\mathrm{SO}_{2}$ plume altitude retrievals for the Raikoke volcano 2019 eruption were gridded onto a $1 \times 1^{\circ}$ grid at $3 \mathrm{~h}$ intervals per day. The equivalent $\mathrm{CAMS}_{\mathrm{SO}} \mathrm{Plume}$ altitude, i.e. the altitude where the maximum $\mathrm{SO}_{2}$ load occurs in the $\mathrm{CAMS} \mathrm{SO}_{2}$ profiles, was chosen for the collocations. In

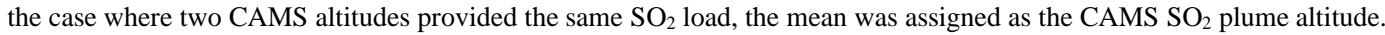




\section{CAMS model and data assimilation system}

\subsection{CAMS model}

The chemical mechanism of ECMWF's Integrated Forecast System (IFS) is a modified and extended version of the Carbon Bond 2005 chemistry scheme (CB05, Yarwood et al. 2005) chemical mechanism for the troposphere, as also implemented in the chemical transport model (CTM) TM5 (Huijnen et al., 2010). CB05 is a tropospheric chemistry scheme with 57 species and 131 reactions. The chemistry module of the IFS is documented in more detail in Flemming et al. (2015) and Flemming et al. (2017) and more recent updates in Inness et al. (2019). The CB05 chemistry scheme is coupled to the AER aerosol bulk scheme (Remy et al. 2019) for the simulation of sulphate, nitrate and ammonium aerosols. More up-to-date information is available from atmosphere.copernicus.eu. In the model version used in this paper, the CAMS system uses the CAMSGLOBANTv4.2 anthropogenic emissions (Granier et al., 2019) which include anthropogenic $\mathrm{SO}_{2}$, as well as a climatology of $\mathrm{SO}_{2}$ outgassing volcanic emissions based on satellite retrievals (Carn et al., 2016).

\subsection{CAMS data assimilation system}

The IFS uses an incremental four-dimensional variational (4D-Var) data assimilation system (Courtier et al. 1994). $\mathrm{SO}_{2}$ is one of the atmospheric composition fields that is included in the control vector and minimized together with the

210 meteorological control variables in the CAMS system (Inness et al., 2015, Flemming and Inness, 2013). The current operational CAMS configuration uses a weak constraint formulation of 4D-Var which includes a model error term for the meteorological variables (Laloyaux et al., 2020) that corrects mainly the stratospheric temperature bias and also improves slightly the stratospheric winds. In the CAMS 4D-Var system, the control variables are the initial conditions at the beginning of the assimilation window, with the aim of providing the best initial conditions for the subsequent forecast. The background error covariance matrix in the ECMWF data assimilation system is given in a wavelet formulation (Fisher 2004, 2006). This allows both spatial and spectral variations of the horizontal and vertical background error covariances. The CAMS background errors are constant in time. The horizontal resolution of the NRT CAMS 2021 operational system as well as that of the data assimilation experiments presented in this paper is approximately $40 \mathrm{~km}$, corresponding to a triangular truncation of TL511 or a reduced Gaussian grid with a resolution of N256 (more information can be found at https://confluence.ecmwf.int/display/FCST/Gaussian+grids). The operational CAMS system uses two minimisations (the socalled inner loops) at reduced horizontal resolution, currently at TL95 and TL159 corresponding to horizontal resolutions of about $210 \mathrm{~km}$ and $125 \mathrm{~km}$. This means that wavenumbers up to 95/159 can be represented in the wavelet formulation for the background errors. For the experiments presented in this paper, slightly higher horizontal resolutions of TL159/TL255 were used for the inner loops (corresponding to about 125 and $80 \mathrm{~km}$, respectively). The CAMS model and data assimilation system has 137 model levels in the vertical, between the surface and $0.01 \mathrm{hPa}$ and uses a 12-hour 4D-Var configuration with assimilation windows from 3 to 15 UTC and from 15-3 UTC.

\subsubsection{CAMS NRT TCSO 2 assimilation configuration (baseline configuration)}

The $\mathrm{SO}_{2}$ data assimilated in the CAMS NRT configuration are total column values. To calculate the model equivalent of the observations the CAMS $\mathrm{SO}_{2}$ field is interpolated to the time and location of the measurements and the $\mathrm{CAMS} \mathrm{SO}_{2}$ columns are calculated as a simple vertical integral between the surface and the top of the atmosphere. While the background error statistics for most of the atmospheric composition fields (Inness et al., 2015) were either calculated with the National Meteorological Center (NMC) method (Parrish and Derber, 1992) or from an ensemble of forecast differences (following a method described by Fisher and Andersson, 2001), the background errors for $\mathrm{SO}_{2}$ are prescribed by an analytical vertical standard deviation profile and horizontal correlations. $\mathrm{SO}_{2}$ observations are currently only assimilated in the CAMS system 
235 in the event of volcanic eruptions, i.e. when the observed $\mathrm{SO}_{2}$ concentrations are considerably larger than the atmospheric background values. An NMC or ensemble approach would not give useful $\mathrm{SO}_{2}$ background error statistics in these cases as the forecast model does not have information about individual volcanic eruptions, even though it does include emissions from outgassing volcanoes. $\mathrm{SO}_{2}$ background error standard deviations calculated with the $\mathrm{NMC}$ or ensemble methods peak near the surface where anthropogenic $\mathrm{SO}_{2}$ concentrations are largest and will hence lead to the largest analysis increments

240 near the surface. Therefore, for the assimilation of volcanic $\mathrm{SO}_{2}$ data, background error statistics for $\mathrm{SO}_{2}$ were constructed by prescribing a background error standard deviation profile that is a delta function and peaks in the mid troposphere around model level 98 (about $550 \mathrm{hPa}$ ) in the 137 level model version, corresponding to an $\mathrm{SO}_{2}$ injection height of about $5 \mathrm{~km}$ (see blue profile in Figure 1).

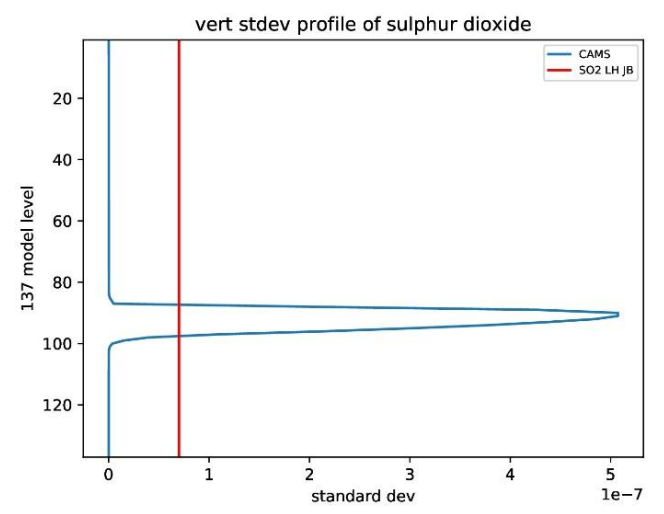

245 Figure 1: Vertical profile of $\mathrm{SO}_{2}$ background error standard deviation in $\mathrm{kg} / \mathrm{kg}$ used in the operational CAMS configuration (blue) and for the main LH experiment (red, LHexp). The y-axis shows model levels. Level 1 is the top of the atmosphere, level 137 the surface.

The $\mathrm{SO}_{2}$ wavelet file in the NRT CAMS configuration (also called baseline configuration in this paper) is formed of diagonal vertical wavenumber correlation matrices, with the value on the diagonal controlled by a horizontal Gaussian correlation function with a standard deviation of $250 \mathrm{~km}$ and a globally constant vertical standard deviation profile. The values of the elements on the diagonal of the vertical correlation matrix are the same at every level but vary for each wavenumber. If $\mathrm{TCSO}_{2}$ data are assimilated the largest correction to the model's background will be applied where the

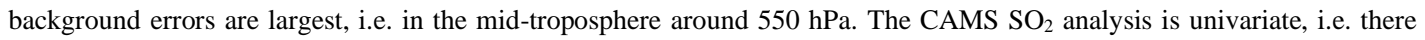
are no cross correlations between $\mathrm{SO}_{2}$ background errors and the other atmospheric composition control variables.

\subsubsection{Data assimilation configuration for $\mathrm{TCSO}_{2} \mathrm{LH}$ data}

If information about the altitude of the volcanic $\mathrm{SO}_{2}$ layer is known in NRT a different approach can be followed. In this case, we use a background error standard deviation profile that is constant in height (e.g. red line in Fig. 1) and calculate the $\mathrm{SO}_{2}$ column not between the surface and the top of the atmosphere, but between the pressure values that correspond to the bottom and the top of the retrieved volcanic $\mathrm{SO}_{2}$ layer. The depth of this layer is currently set in the FP_ILM retrieval as 2 $\mathrm{km}$, which corresponds to the uncertainty of the retrieved layer height. This approach mimics the procedure of using averaging kernels with box profiles given for the $\mathrm{SO}_{2}$ layer. Results from sensitivity studies regarding the choice of the constant background error standard deviation value are given below in Section 4.2. 


\section{Assimilation of TROPOMI TCSO 2 data for 2019 Raikoke eruption}

\subsection{Raikoke eruption June 2019}

The Raikoke volcano, located on the Kuril Islands south of the Kamchatka peninsula, erupted around 18 UTC on 21 June 2019 and emitted $\mathrm{SO}_{2}$ and ash in a series of explosive events until about 6 UTC on 22 July. The $\mathrm{SO}_{2}$ and ash plume rose to around 8-18 km (Muser et al., 2020; Grebennikov et al., 2020) meaning a considerable amount of the $\mathrm{SO}_{2}$ reached the stratosphere. The volcanic cloud was transported around much of the northern hemisphere, was observed by TROPOMI and GOME-2 for about a month and was also observed with ground-based measurements (Vaughan et al., 2021; Grebennikov et al., 2020) and other satellites (Muser et al., 2020). Figure 2 shows the $\mathrm{TCSO}_{2}$ burden from the Raikoke eruption as calculated from NRT TROPOMI and GOME-2B data. The satellite data were gridded onto a $1^{\circ} \mathrm{x} 1^{\circ}$ degree grid and the area of all grid cells with $\mathrm{SO}_{2}$ values greater than the listed threshold values was calculated. For a threshold of $1 \mathrm{DU}$ the $\mathrm{SO}_{2}$ burdens from TROPOMI and GOME-2B were around $1.5 \mathrm{Tg}$ and $1.1 \mathrm{Tg}$, respectively. These values agree with findings by de Leeuw et al. (2020) and make the eruption the largest since the eruption of the Nabro volcano in 2011 (de Leeuw et al, 2020; Goitom et al, 2015; Clarisse et al., 2014). The 'dip' in the TROPOMI SO2 burden after the initial peak is an artefact that results from missing observations in the TROPOMI NRT data.
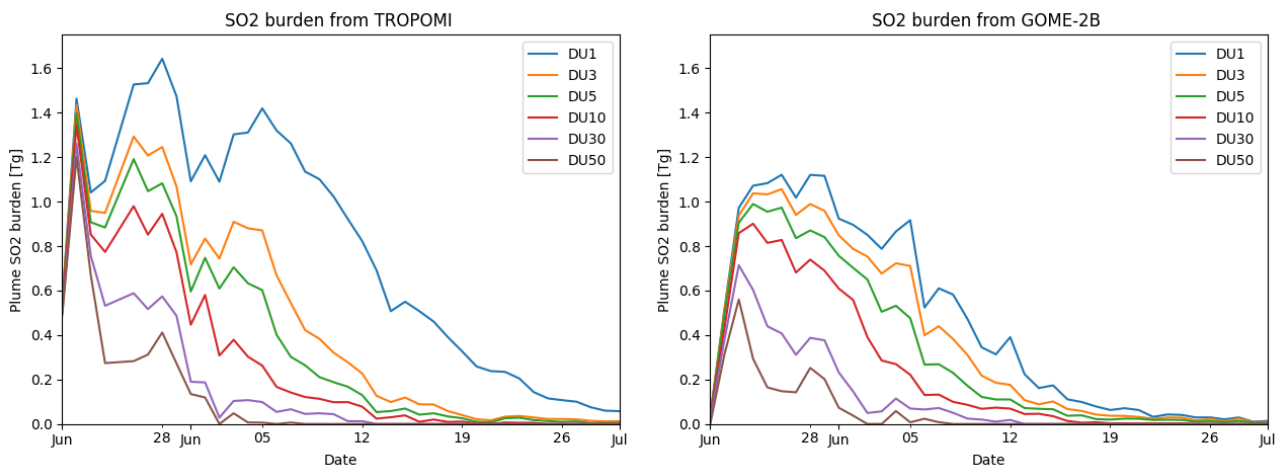

Figure 2: $\mathrm{SO}_{2}$ burden (in Tg) from TROPOMI (left) and GOME-2B (right) from 22 June to 31 July 2031. The values are calculated by gridding the data on a $1^{0} \mathrm{x} 1^{\circ}$ grid and selecting the grid cells with $\mathrm{TCSO}_{2}$ values greater than thresholds of $1,3,5,10$, 30 and $50 \mathrm{DU}$ in the area $30-90^{\circ} \mathrm{N}$.

Figure 3 shows a timeseries of the $\mathrm{SO}_{2} \mathrm{LH}$ information that was retrieved for the Raikoke plume from TROPOMI with the FP_ILM retrieval. It shows that volcanic $\mathrm{SO}_{2}$ can be detected and the $\mathrm{SO}_{2} \mathrm{LH}$ information retrieved for about 3 weeks after the eruption. The bulk of the $\mathrm{SO}_{2}$ was located above $300 \mathrm{hPa}$, (about $9 \mathrm{~km}$ ) with a considerable amount above $200 \mathrm{hPa}$ (about $12 \mathrm{~km}$ ). This is considerably higher than the $550 \mathrm{hPa}$ that is assumed as the plume location in the CAMS operational (baseline) configuration. Large $\mathrm{TCSO}_{2}$ values (>100 DU) were observed in the first days after the eruption. 


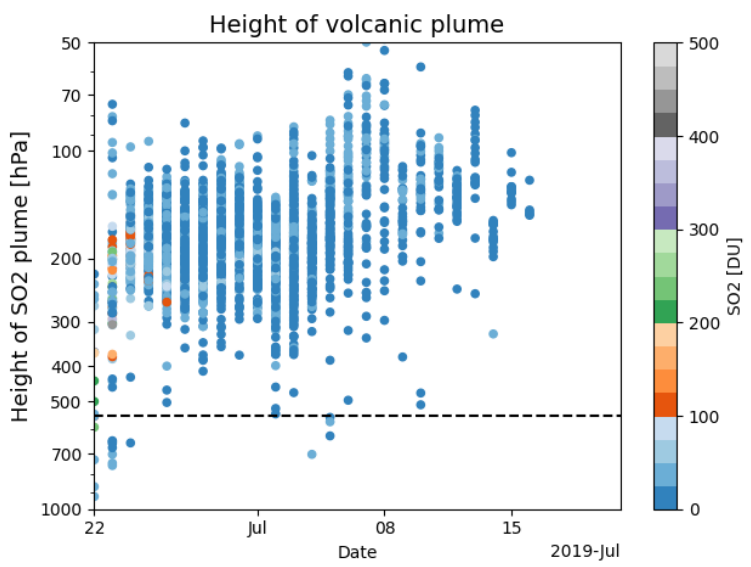

Figure 3: Timeseries of the height of the Raikoke volcanic plume (averaged over $30-90^{\circ} \mathrm{N}$ ) in $\mathrm{hPa}$ from TROPOMI $\mathrm{SO}_{2} \mathrm{LH}_{\text {data }}$ from 22 June to 21 July 2019. The colours show the corresponding $\mathrm{TCSO}_{2}$ values in DU. The dashed horizontal line at $550 \mathrm{hPa}$ shows the altitude where the CAMS baseline configuration places the maximum $\mathrm{SO}_{2}$ increment.

\subsection{Sensitivity studies for assimilation of $\mathrm{TCSO}_{2}$ data}

Several data assimilation experiments were run for the period 22 June to 21 July 2019 to test the assimilation of the $\mathrm{SO}_{2} \mathrm{LH}$ data and to compare the results with the CAMS baseline configuration, listed in Table 3. The baseline experiment (BLexp)

\begin{tabular}{|l|l|l|l|l|l|}
\hline $\begin{array}{l}\text { Experiment } \\
\text { Abbreviation }\end{array}$ & $\begin{array}{l}\text { Experiment ID, } \\
\text { DOI }\end{array}$ & $\begin{array}{l}\text { Assimilated } \\
\text { data }\end{array}$ & $\begin{array}{l}\text { Bg-error } \\
\text { stdv }[\mathrm{kg} / \mathrm{kg}]\end{array}$ & $\begin{array}{l}\text { Bg-error } \\
\text { hcor }[\mathrm{km}]\end{array}$ & $\begin{array}{l}\text { Resolution of } \\
\text { minimisations }\end{array}$ \\
\hline BLexp & $\begin{array}{l}\text { hhu5, } \\
10.21957 / \text { cygt-xf49 }\end{array}$ & S5P NRT > 5DU & $\begin{array}{l}\text { CAMS } \\
\text { (see Fig. 2) }\end{array}$ & 250 & TL159, TL255 \\
\hline LHexp & $\begin{array}{l}\text { hgze, } \\
10.21957 / \text { qfam-7474 }\end{array}$ & S5P LH >20DU & $0.7 \mathrm{e}^{-7}$ & 100 & TL159, TL255 \\
\hline LH50 & $\begin{array}{l}\text { hhbu, } \\
10.21957 / \text { zpdt-f079 }\end{array}$ & S5P LH > 20DU & $1 \mathrm{e}^{-7}$ & 50 & TL159, TL255 \\
\hline LH100 & $\begin{array}{l}\text { hhtm, } \\
10.21957 / \text { jraa-s174 }\end{array}$ & S5P LH> 20DU & $1 \mathrm{e}^{-7}$ & 100 & TL159, TL255 \\
\hline LH250 & $\begin{array}{l}\text { hhtn, } \\
10.21957 / \text { ddxs-2v95 }\end{array}$ & S5P LH > 20DU & $1 \mathrm{e}^{-7}$ & 250 & TL159, TL255 \\
\hline LH1.4 & $\begin{array}{l}\text { hgz7, } \\
10.21957 / 81 \mathrm{bh}-7 h 58\end{array}$ & S5P LH > 20DU & $1.4 \mathrm{e}^{-7}$ & 100 & TL159, TL255 \\
\hline
\end{tabular}

Table 3: List of $\mathrm{SO}_{2}$ assimilation experiments used in this paper. The main experiments discussed in Section 4 are the baseline experiment (BLexp) and the layer height experiment (LHexp). The additional experiments are used in the sensitivity studies in Section 4.2. Bg-error denotes background error, stdv standard deviation and hcor horizontal correlation length scale.

which assimilated NRT TROPOMI $\mathrm{TCSO}_{2}$ data with the operational CAMS configuration and the layer height experiment (LHexp) which uses the FP_ILM S5P LH data with a horizontal background error correlation length of $100 \mathrm{~km}$ and background error standard deviation values of $0.7 \mathrm{e}^{-7} \mathrm{~kg} / \mathrm{kg}$ are the main experiments used in this paper (Section 4.3 below) to assess if the assimilation of the $\mathrm{SO}_{2} \mathrm{LH}$ data improves the CAMS $\mathrm{SO}_{2}$ analyses and forecasts. The other $\mathrm{LH}$ experiments assess the impact of using different horizontal $\mathrm{SO}_{2}$ background error correlation length scales and various $\mathrm{SO}_{2}$ background 
error standard deviation values. In all these experiments GOME-2 $\mathrm{SO}_{2}$ data were not assimilated, and GOME-2B is used as a

The low resolution of the minimisation (TL95/TL159 in the CAMS system operational in 2021) is a factor that limits the ability of the $\mathrm{SO}_{2}$ analysis to reproduce small-scale $\mathrm{SO}_{2}$ features seen in the observations because it gives a lower limit for the length scale of the horizontal background error correlations that can be used, i.e. for the operational CAMS configuration only wavenumbers up to $95 / 159$ can be represented. The smallest wavelength $\left(\lambda_{\min }\right)$ that can be represented by two grid points on a linear grid is

$$
\lambda_{\min }=\frac{2 \pi R}{n_{\max }} \quad(1)
$$

where $\mathrm{R}$ is the radius of the Earth and $\mathrm{n}_{\max }$ the maximum wavenumber of the truncation ( 95 or 159 for the inner loops in the operational CAMS configuration), i.e. twice the size of a grid box. This means that the minimum wavelengths which can be represented with two grid points for TL95, TL159 and TL255 are about $420 \mathrm{~km}, 250 \mathrm{~km}, 160 \mathrm{~km}$, respectively and smaller scale horizontal structures cannot be represented in the background error wavelet formulation. Figure 4 illustrates this and shows horizontal $\mathrm{SO}_{2}$ correlations at the surface for horizontal background error length scales of $50 \mathrm{~km}, 100 \mathrm{~km}$ and $250 \mathrm{~km}$ for truncations of TL95, TL159 and TL255. The 'wriggles' seen in the TL95 (and to a lesser extent in the TL159) plots show that the shorter background error correlations length scales cannot be properly resolved at these truncations. Even at TL255 some minor oscillations are still visible for horizontal correlation length scales of $50 \mathrm{~km}$. Therefore, to properly resolve smaller-scale plumes the resolutions of the inner loops would need to be even higher than TL255. Figure 4 also illustrates how far an increment from a single $\mathrm{SO}_{2}$ observation would be spread out in the horizontal and therefore affect grid points away from the observation.
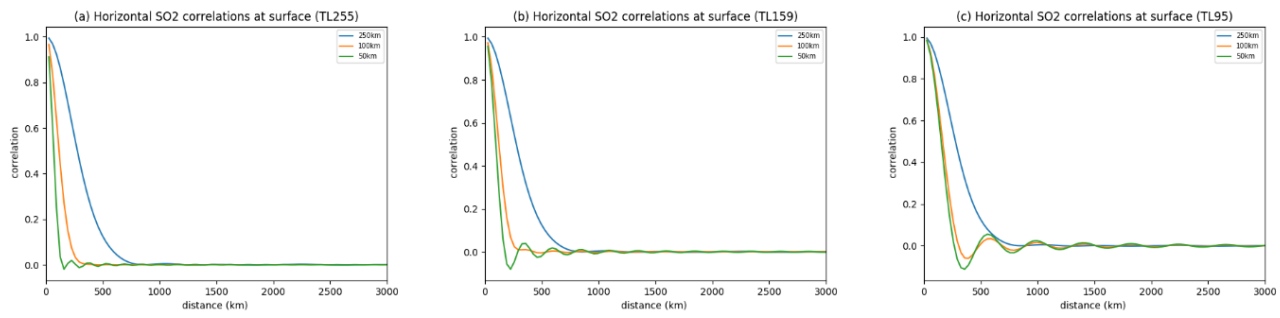

330 Figure 4: $\mathrm{SO}_{2}$ background error horizontal surface correlations at different truncations: (a) TL255, (b) TL159 and (c) TL95 if the horizontal length scales are specified as Gaussian correlation function with length scales of $250 \mathrm{~km}$ (blue), $100 \mathrm{~km}$ (orange) and 50 km (green).

The operational NRT CAMS configuration uses minimisations at TL95/TL159 and a length scale of $250 \mathrm{~km}$ for the horizontal $\mathrm{SO}_{2}$ background error correlations. For the data assimilation experiments shown in this paper we use inner loops of TL159/TL255 to allow us to use a Gaussian correlation function with a length scale of $100 \mathrm{~km}$ and therefore resolve slightly smaller-scale features than in the operational NRT CAMS system. Figure 5 shows the CAMS $\mathrm{TCSO}_{2}$ analysis fields on 27 June 2019 resulting from the assimilation of the TROPOMI $\mathrm{SO}_{2} \mathrm{LH}$ data when horizontal background error correlation length scales of 50, 100 and $250 \mathrm{~km}$ were used (experiments LH50, LH100, LH250), while using the same background error standard deviation profile of $1 \mathrm{e}^{-7} \mathrm{~kg} / \mathrm{kg}$ in all cases. Also shown are the NRT TROPOMI and GOME-2B $\mathrm{TCSO}_{2}$ retrievals for that day. The figure illustrates the large impact of the horizontal background error correlation length scale on the $\mathrm{SO}_{2}$ analysis, as the $\mathrm{SO}_{2}$ plume is considerably more spread out in the CAMS analysis when longer horizontal correlations are used, and that better agreement with the features seen in the observations is found for shorter horizontal correlations. Figure 6 shows timeseries of $\mathrm{SO}_{2}$ burden and plume area for a threshold of 5 DU from TROPOMI, GOME-2B and the three $\mathrm{SO}_{2} \mathrm{LH}$ experiments to further assess the impact on the $\mathrm{SO}_{2}$ analysis of changing the horizontal correlation 


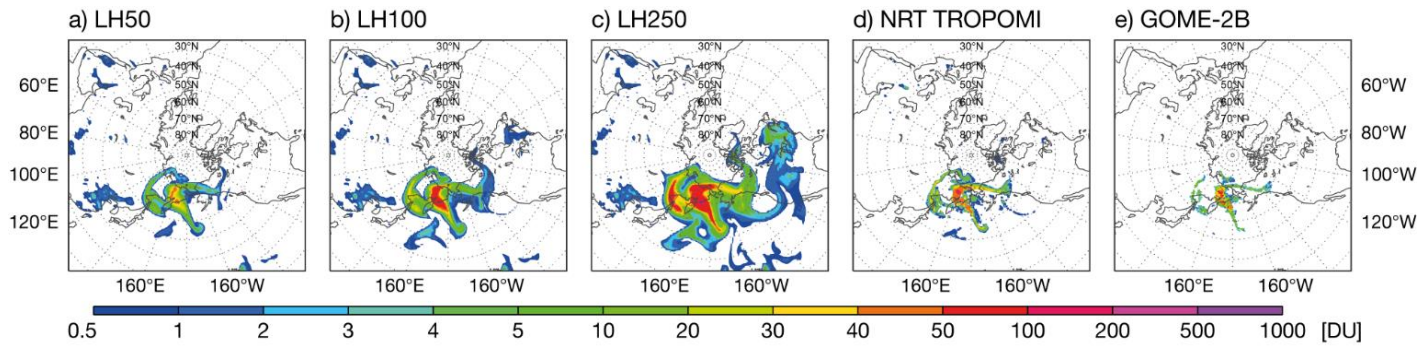

Figure 5: $\mathrm{TCSO}_{2}$ analyses on 27 June 2019 at $0 \mathrm{z}$ obtained by assimilating $\mathrm{SO}_{2} \mathrm{LH}$ data using a background standard deviation profile of $10^{-7} \mathrm{~kg} / \mathrm{kg}$ and background errors with horizontal correlations of (a) $50 \mathrm{~km}$, (b) $100 \mathrm{~km}$ and (c) $250 \mathrm{~km}$. Also shown are (d) NRT TROPOMI and (e) GOME-2B TCSO 2 values.

length scale. We see that the $\mathrm{SO}_{2}$ burden and plume area calculated from the observations are overestimated by all three CAMS $\mathrm{TCSO}_{2}$ analyses. This overestimation is a well-known feature usually seen in the operational NRT CAMS volcanic $\mathrm{SO}_{2}$ assimilation. Figure 6 illustrates that a major factor causing this overestimation is the choice of the horizontal background error correlation length scale and that by choosing a length scale of $250 \mathrm{~km}$ the $\mathrm{SO}_{2}$ burden and plume area are about 6 times larger than for a length scale of $50 \mathrm{~km}$. This implies that a limiting factor for correctly reproducing the $\mathrm{SO}_{2}$ burden and plume area in the CAMS analysis is the resolution of the inner loops as it limits the horizontal correlation length scale that can be chosen for the background errors. A coarser inner loop resolution requires a longer horizontal length scale because shorter wavelengths cannot be resolved properly. If the aim is to reproduce finer-scale volcanic plumes with the CAMS data assimilation system, the horizontal resolution of the inner loops will have to be increased. For the main LH experiment used in this paper we decided to use a horizontal correlation length scale of $100 \mathrm{~km}$ which can be represented properly if the resolutions of the inner loops are TL159/TL255.
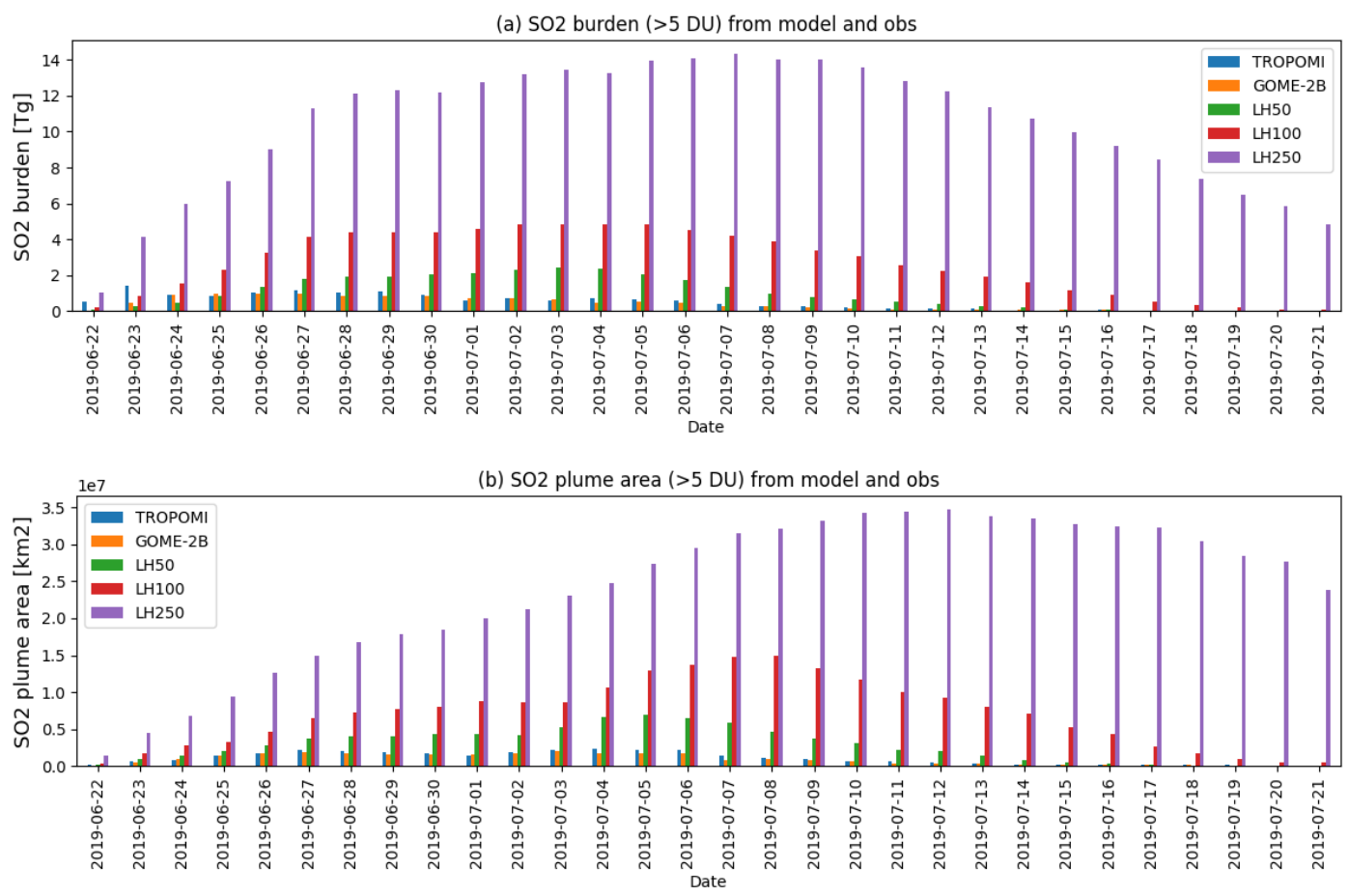

Figure 6: (a) $\mathrm{SO}_{2}$ burden in Tg and (b) plume area in $1 \mathrm{e}^{7} \mathrm{~km}^{2}$ from TROPOMI, GOME-2B and three $\mathrm{SO}_{2} \mathrm{LH}_{\text {experiments at } 0 \mathrm{z}}$ with horizontal background error length scales of $50 \mathrm{~km}$ (LH50), 100km (LH100) and $250 \mathrm{~km}$ (LH250) for the Raikoke eruption (22 June to 21 July 2019). The values are calculated by gridding the data on $\mathbf{a}^{10} \times 1^{0}$ grid and selecting the grid cells with TCSO values greater than $5 \mathrm{DU}$ in the area $30-90^{\circ} \mathrm{N}$. 
Another factor that influences the results of the $\mathrm{SO}_{2}$ analysis is the value of the background error standard deviation profile. This is illustrated in Figure 7 which shows time series of $\mathrm{SO}_{2}$ burden and plume area from TROPOMI, GOME-2B and three $\mathrm{O}_{2} \mathrm{LH}$ experiments with varying background error standard deviation values $\left(0.7 \mathrm{e}^{-7}, 1.0 \mathrm{e}^{-7}, 1.4 \mathrm{e}^{-7} \mathrm{~kg} / \mathrm{kg}\right)$. All experiments used a horizontal background error correlation length scale of $100 \mathrm{~km}$. The larger the background error standard deviation, the larger the correction that is made by the $\mathrm{SO}_{2}$ analysis and the larger the $\mathrm{SO}_{2}$ burden and plume area become. However, the impact of changing the background error standard deviation is not as big as changing the horizontal background error correlation length scale and increasing the standard deviation value from $0.7 \mathrm{e}^{-7} \mathrm{~kg} / \mathrm{kg}$ to $1.4 \mathrm{e}^{-7} \mathrm{~kg} / \mathrm{kg}$ doubles the $\mathrm{SO}_{2}$ burden and plume area.

(a) SO2 burden (>5 DU) from model and obs
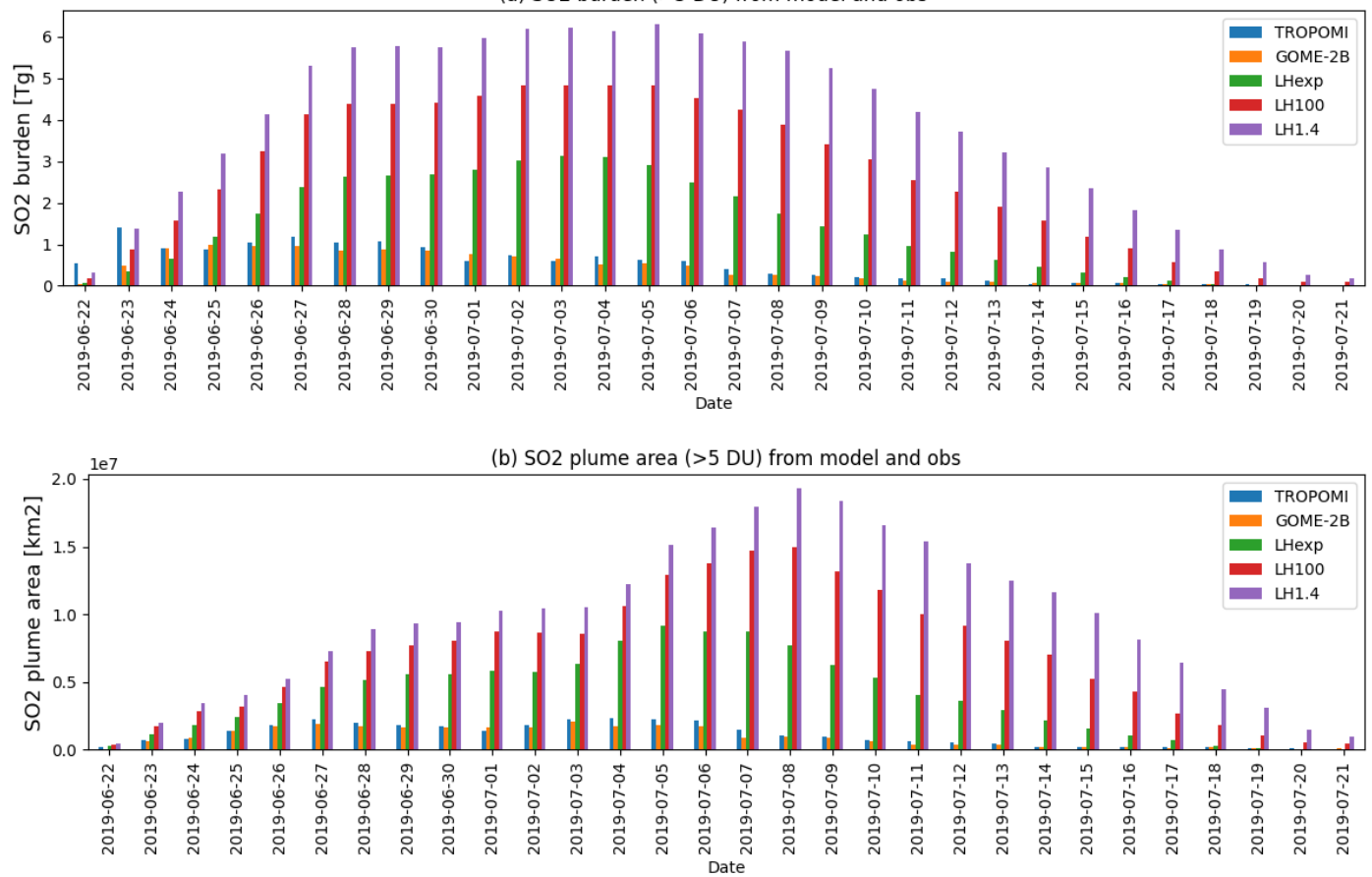

Figure 7: (a) $\mathrm{SO}_{2}$ burden in Tg and (b) plume area in $1 \mathrm{e}^{7} \mathrm{~km}^{2}$ from TROPOMI, GOME-2B and three $\mathrm{SO}_{2} \mathrm{LH}_{\text {experiments at } 0 \mathrm{z}}$ with background error standard deviation values of $0.7 \mathrm{e}^{-7}$ (LHexp), $1 \mathrm{e}^{-7}$ (LH100) and 1.4e $\mathrm{C}^{-7} \mathrm{~kg} / \mathrm{kg}$ (LH1.4) for the Raikoke eruption (22 June to 21 July 2019). The values are calculated by gridding the data on a $1^{0} \times 1^{\circ}$ grid and selecting the grid cells with $\mathrm{TCSO}_{2}$ values greater than $5 \mathrm{DU}$ in the area $30-90^{\circ} \mathrm{N}$.

For the remainder of this paper the LH experiment that uses a value of $0.7 \mathrm{e}-7 \mathrm{~kg} / \mathrm{kg}$ for the background error standard deviation and a horizontal background error correlation length scale of $100 \mathrm{~km}$ is used (abbreviated as LHexp).

\subsection{Results of $\mathrm{TCSO}_{2}$ assimilation tests for the Raikoke 2019 eruption}

The $\mathrm{SO}_{2}$ analysis fields and 5-day forecasts for the Raikoke eruption from the $\mathrm{SO}_{2}$ layer height experiment (LHexp) and the baseline experiment with the CAMS configuration (BLexp) are now assessed in more detail. This assessment includes (1) a visual inspection of the $\mathrm{SO}_{2}$ analysis, (2) the assessment of the vertical location of the analysis $\mathrm{SO}_{2}$ plume by comparison with independent IASI/ MetOp plume height observations and (3) the assessment of the quality of the 5-day $\mathrm{SO}_{2}$ forecasts that are started from the LHexp and BLexp $\mathrm{SO}_{2}$ analyses. 
We evaluate the $\mathrm{SO}_{2}$ analyses and forecasts against GOME-2B and TROPOMI NRT TCSO retrievals. GOME-2B TCSO data are fully independent because they are not used in our $\mathrm{SO}_{2}$ assimilation experiments, and TROPOMI NRT TCSO retrievals are useful to demonstrate in how far the analyses manage to reproduce the TROPOMI $\mathrm{TCSO}_{2}$ values. It has to be kept in mind that the version of the FP_ILM SO 2 LH retrieval used in this study (v3.1) attains its optimal accuracy of $2 \mathrm{~km}$ for $\mathrm{SO}_{2}$ columns greater than $20 \mathrm{DU}$ and hence, in $\mathrm{LHexp}$, no $\mathrm{TCSO}_{2}$ observations below $20 \mathrm{DU}$ are assimilated. For the evaluation, the $\mathrm{SO}_{2}$ analyses and forecasts, as well as the satellite data, are gridded onto a $1^{0} \mathrm{x} 1^{\circ}$ grid. Figure 8 shows a timeseries of the number of observations that are actively assimilated in both experiments, i.e. the number of $1^{\circ} \mathrm{x} 1^{0} \mathrm{grid}$ points with active observations, and illustrates that there are more active data in BLexp where NRT TROPOMI $\mathrm{SO}_{2}$ data with values greater than $5 \mathrm{DU}$ are assimilated (i.e. as done in the operational CAMS system) than in LHexp where only data with $\mathrm{LH} \mathrm{TCSO}_{2}$ greater than $20 \mathrm{DU}$ are assimilated.

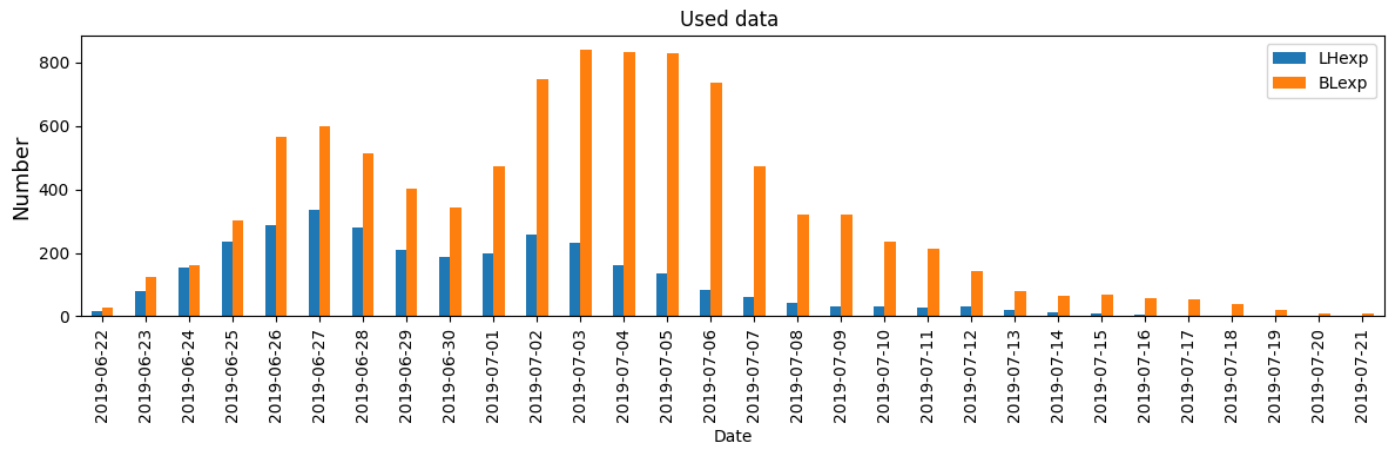

Figure 8: Timeseries of number of active TROPOMI $\mathrm{SO}_{2}$ observations assimilated in LHexp (blue) and BLexp (orange) both gridded on a $1^{0} \times 1^{0}$ grid.

\subsubsection{Evaluation of $\mathrm{TCSO}_{2}$ analyses}

Figure 9 shows $\mathrm{TCSO}_{2}$ maps from LHexp and BLexp as well as maps of $\mathrm{TCSO}_{2}$ from NRT TROPOMI, GOME-2B and FP_ILM TROPOMI $\mathrm{SO}_{2} \mathrm{LH}$ retrievals for 4 days: 22, 25, 29 June and 4 July 2019. The maps on 22 June capture the beginning of the eruption and show that the $\mathrm{TCSO}_{2}$ values from the first analysis cycle in both experiments are lower than the observations. It also illustrates that even at this initial time the extent of the $\mathrm{SO}_{2}$ plume is overestimated in both experiments. By 25 and 29 June the $\mathrm{SO}_{2}$ plume already covers a big part of the North Pacific and by 4 July $\mathrm{SO}_{2}$ from the eruption is detected in half the northern hemisphere. LHexp captures the structures of the $\mathrm{SO}_{2}$ plumes seen in the observations better than BLexp, but overall, both experiments capture the horizontal extent of the plume reasonably well. Figure 9 also illustrates that GOME-2B and NRT TROPOMI $\mathrm{TCSO}_{2}$ show the same features of the plume, however the

415 TROPOMI NRT lower detection limit facilitates the retrieval of smaller $\mathrm{TCSO}_{2}$ values around the edges of the plumes. The FP_ILM SO $2 \mathrm{LH}$ retrieval (v3.1) does not provide reliable information for $\mathrm{TCSO}_{2}<20 \mathrm{DU}$ and therefore only picks up those parts of the plume that are associated with the highest $\mathrm{SO}_{2}$ load. This also explains the lower number of active observations seen in Fig.8. Especially during the later stages of the eruption parts of the plume are missed by the FP_ILM $\mathrm{SO}_{2} \mathrm{LH}$ retrieval. Nevertheless, when assimilating the FP_ILM SO 2 LH data we find good agreement with the NRT TROPOMI data and the GOME-2B data in LHexp (Fig. 9, column 1) when the CAMS analysis reports $\mathrm{SO}_{2}$ values < 20DU.

Figure 10 shows timeseries of the $\mathrm{SO}_{2}$ burden from NRT TROPOMI, GOME-2B and the two experiments calculated for threshold values of $5 \mathrm{DU}$ and $30 \mathrm{DU}$, and Figure 11 shows the corresponding timeseries of the plume areas. For the lower 
threshold of $5 \mathrm{DU}$ both the $\mathrm{SO}_{2}$ burden and the plume area are overestimated in LHexp and BLexp. This confirms what was
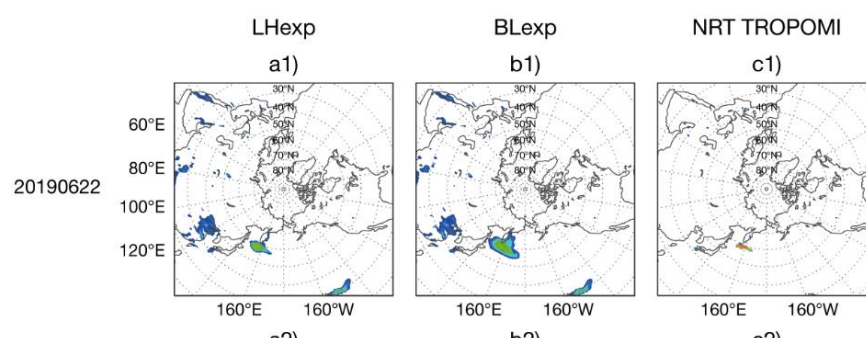

GOME-2B

SO2LH TROPOMI

20190625

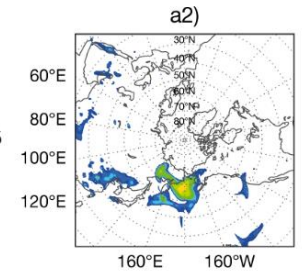

b2)
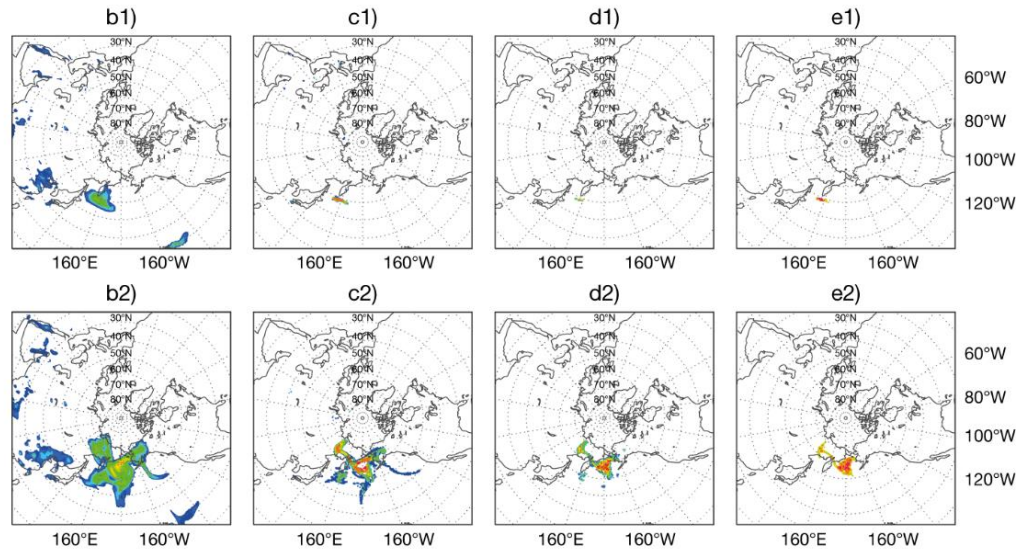

c2)
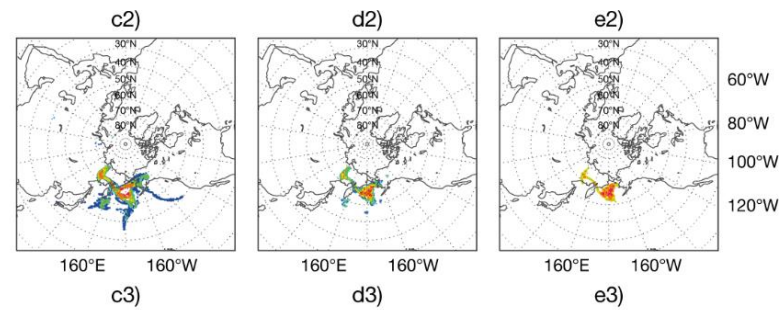

a3)

b3)

c3)
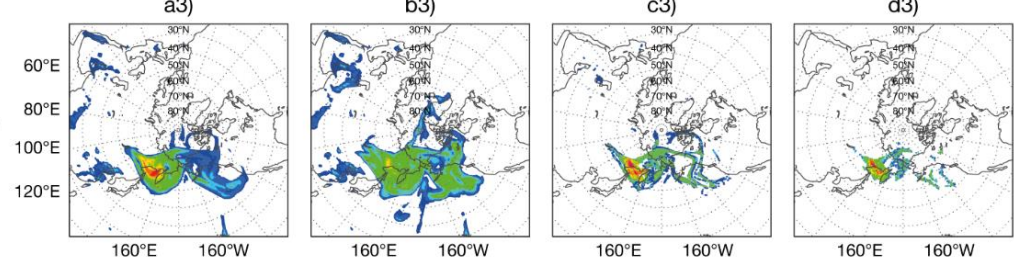

b4)

c4)

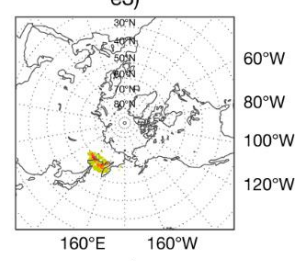

a4)

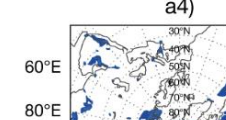

20190704
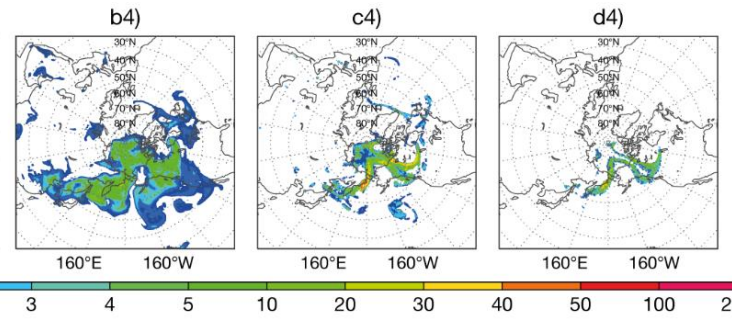

e4)

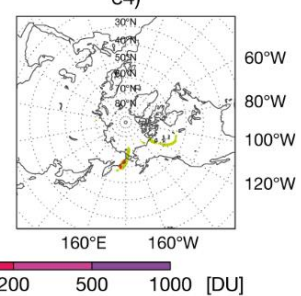

Figure 9: $\mathrm{TCSO}_{2}$ analysis fields at 0z from LH exp (a), BL experiment (b), NRT TROPOI (c), NRT GOME-2B (d) and TROPOMI $\mathrm{SO}_{2} \mathrm{LH}$ (e) on 22 June (row 1), 25 June (row 2), 29 June (row 3) and 4 July (row 4) in DU.

already seen in Figures 6 to 8, namely that the plumes are more spatially dispersed in the analysis than in the observations.

The overestimation of the $\mathrm{SO}_{2}$ burden is larger in LHexp than in BLexp with maximum values of $3 \mathrm{Tg}$ and $2 \mathrm{Tg}$, respectively, compared to 1.5 and 1.2 Tg for NRT TROPOMI and GOME-2B. However, the plume area is larger in BLexp with maximum extent of about $1 \mathrm{e}^{7} \mathrm{~km}^{2}$, compared to $0.8 \mathrm{e}^{7} \mathrm{~km}^{2}$ in LHexp and $0.2 \mathrm{e}^{7} \mathrm{~km}^{2}$ calculated from the observations. BLexp fails to capture the higher $\mathrm{SO}_{2}$ column values, leading to an underestimation of plume area and $\mathrm{SO}_{2}$ burden for a threshold of $30 \mathrm{DU}$, while LHexp does have $\mathrm{TCSO}_{2}$ values $>30 \mathrm{DU}$ but overestimates both plume area and $\mathrm{SO}_{2}$ burden.

To quantify the realism of the $\mathrm{SO}_{2}$ analyses and the quality of the $\mathrm{SO}_{2}$ forecasts appropriate error measures need to be defined and used in addition to the visual inspection of the $\mathrm{SO}_{2}$ plumes. Statistical measures such as bias and root mean square error are not well suited because of the specific event character of the $\mathrm{SO}_{2}$ plumes. In addition to looking at the plume area and $\mathrm{SO}_{2}$ burden, we use threshold-based measures based on the number of hits (grid boxes where both model and observations detect the plume), misses (grid boxes where there is a plume in the observations but not in the model) or false alarms (grid boxes where the model has volcanic $\mathrm{SO}_{2}$ that is not seen in the observations) to quantify the error in the plume position. In Flemming and Inness (2013) we used hits and plume area measures for various thresholds. In this paper we combine the information about hits and misses and use as score the probability of detection (POD) 
(a) SO2 burden (>5 DU) from model and obs

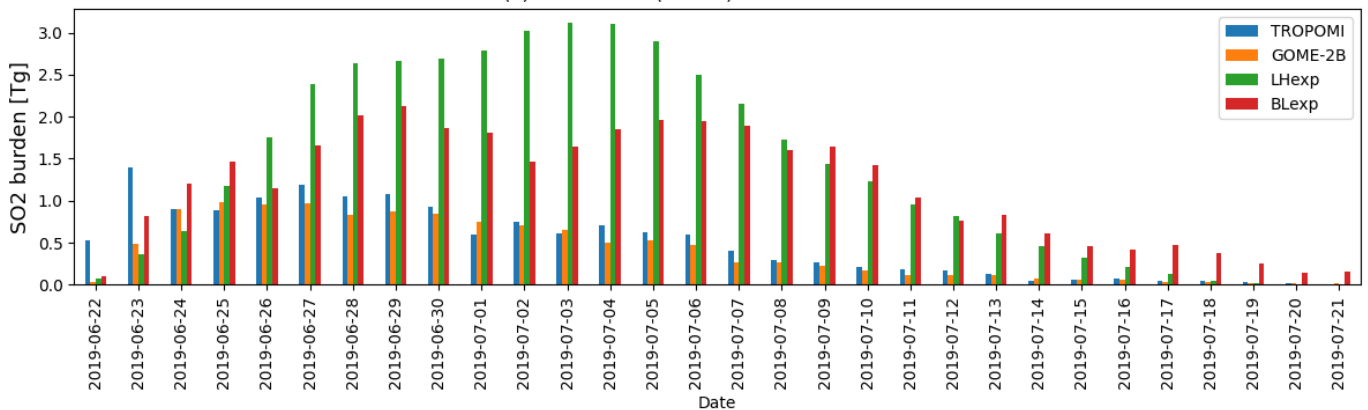

(b) SO2 burden (>30 DU) from model and obs

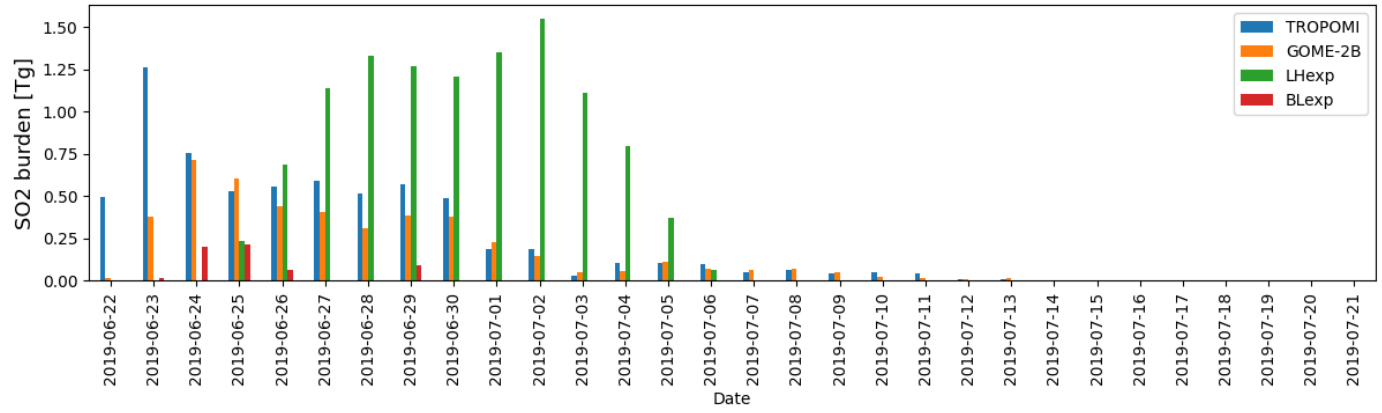

Figure 10: $\mathrm{SO}_{2}$ burden in Tg from TROPOMI, GOME-2B, LHexp and BLexp $\mathrm{TCSO}_{2}$ analysis at $0 \mathrm{z}$ for the Raikoke eruption (22 June to 21 July 2019). The values are calculated by gridding the data on a $1^{\circ} \mathrm{x}^{\circ}$ grid and selecting the grid cells with $\mathrm{TCSO}_{2}$ values greater than (a) $5 \mathrm{DU}$ and (b) $30 \mathrm{DU}$ in the area $30-90^{\circ} \mathrm{N}$.
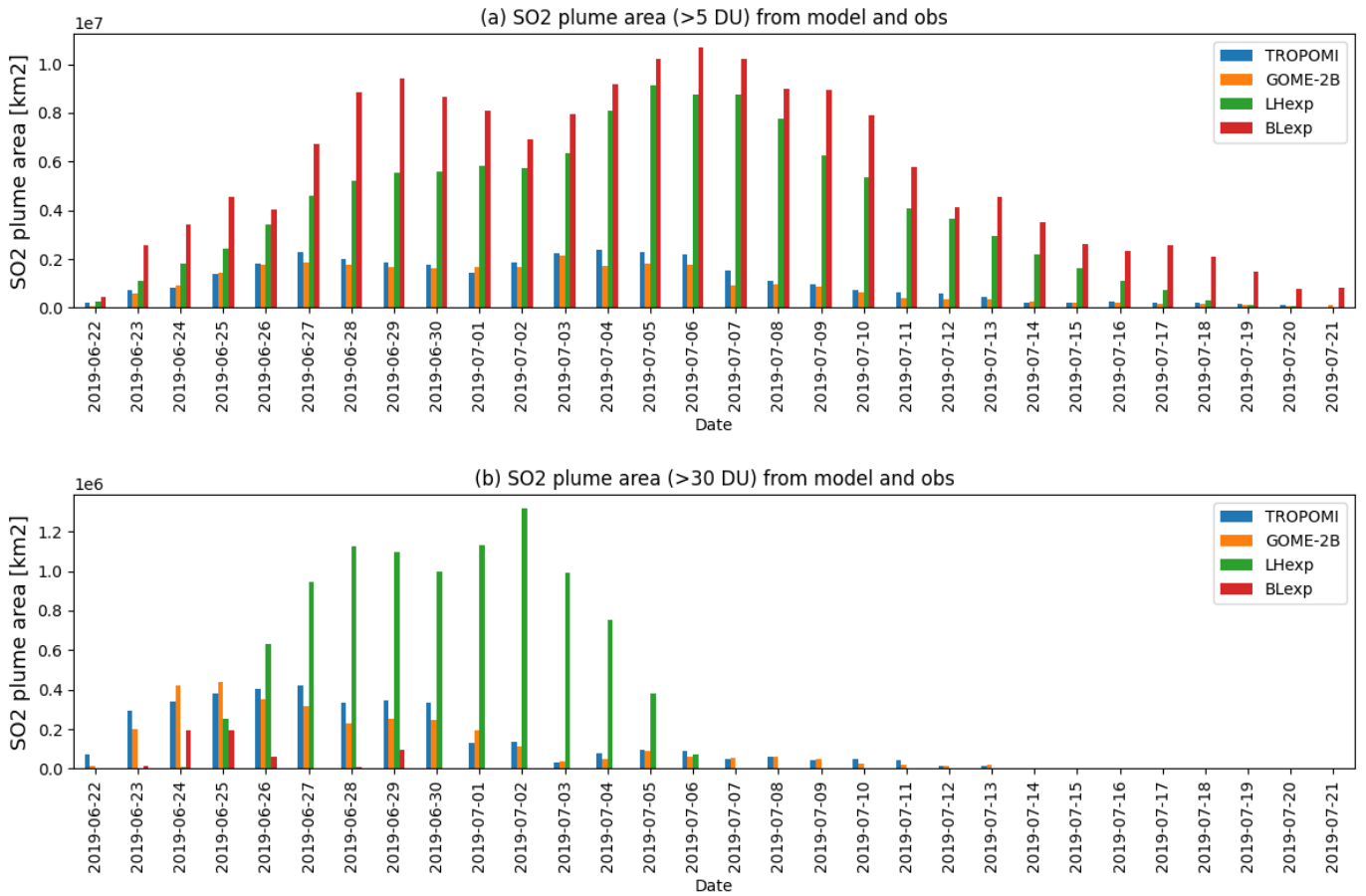

Figure 11: $\mathrm{SO}_{2}$ plume area $\left[\mathrm{km}^{2}\right]$ from TROPOMI, GOME-2B, LHexp and BLexp $\mathrm{TCSO}_{2}$ analysis at 0z for the Raikoke eruption (22 June to 21 July 2019). The values are calculated by gridding the data on a $1^{\circ} \times 1^{\circ}$ grid and selecting the grid cells with $\mathrm{TCSO}_{2}$ values greater than (a) $5 \mathrm{DU}$ and (b) $30 \mathrm{DU}$ in the area $30-90^{\circ} \mathrm{N}$. 
which lies between 0 and 1 , with a value of 1 indicating a perfect score. We also us the critical success index (CSI), defined as

CSI=hits/(hits+misses+false alarms) (3)

which additionally considers the number of false alarms and again has values between 0 and 1 with 1 indicating a perfect score (Nurmi, 2003). These are point based comparisons and might score badly for features that are close but slightly misplaced between observations and model.
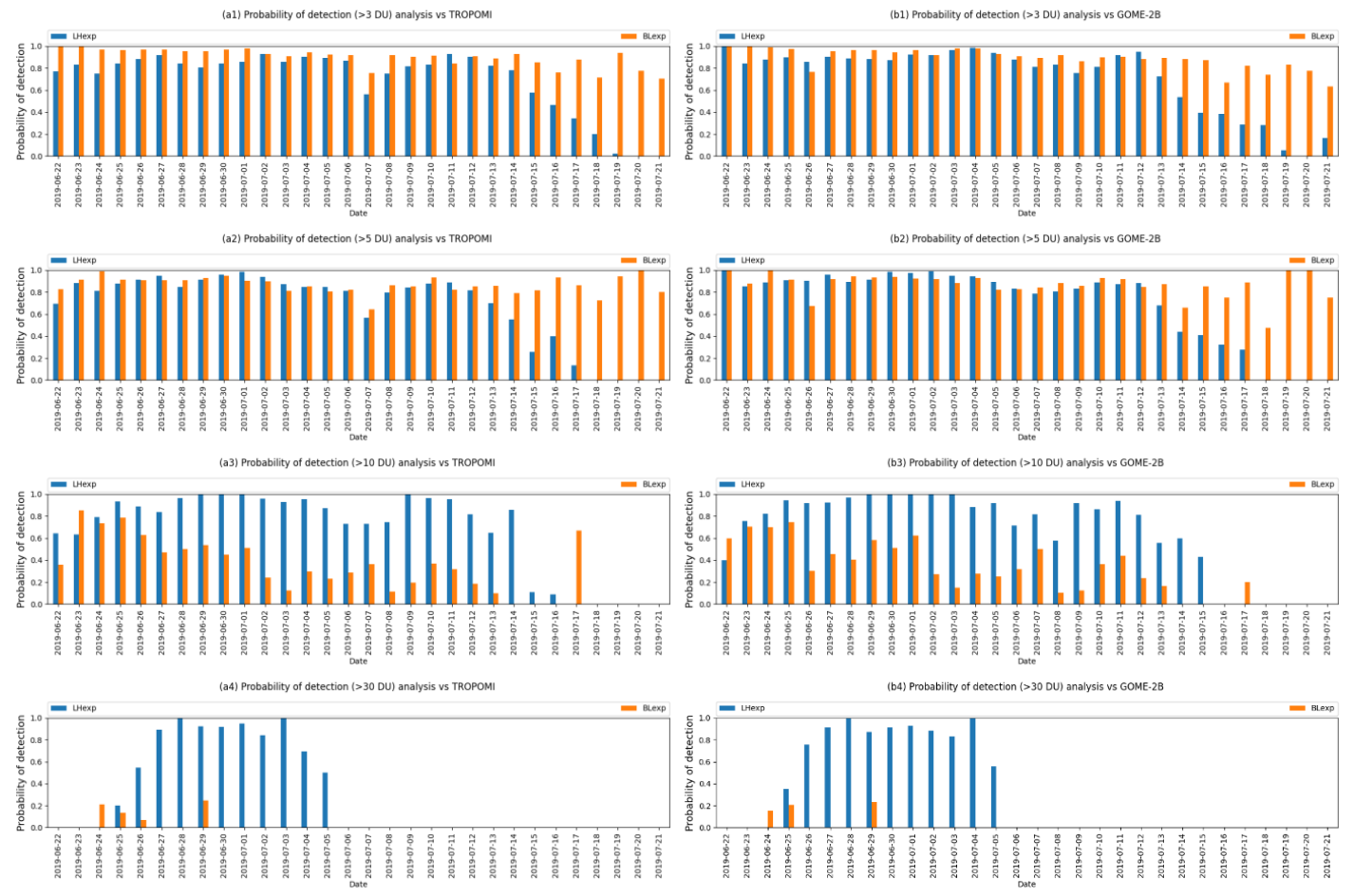

Figure 12: Timeseries of POD for $\mathrm{TCSO}_{2}$ analysis fields (at 0z) against (a) NRT TROPOMI and (b) GOME-2B for TCSO thresholds of (1) 3DU, (2) $5 \mathrm{DU}$, (3) $10 \mathrm{DU}$ and (4) $30 \mathrm{DU}$. Values for LHexp are shown in blue, values for BLexp in orange.

Figure 12 shows the POD from LHexp and BLexp for various $\mathrm{TCSO}_{2}$ analysis thresholds $(3,5,10,30 \mathrm{DU})$ scored against NRT TROPOMI and GOME-2B data. The results are very similar for both satellites. The parts of the plume with lower $\mathrm{TCSO}_{2}$ values are well captured by both experiments with POD values above 0.9 for BLexp for most of the period and POD values above 0.8 for LHexp. The POD in LHexp decreases towards the end of the depicted period because the number of assimilated data drops strongly (see Fig. 8), while more observations are assimilated in BLexp at the later stage of the episode. BLexp, however, does not capture the higher values observed by NRT TROPOMI and GOME-2B well while LHexp has a much higher POD for those parts of the plume. No values above 30 DU are detected after 5 July 2019.

Figure 13 shows the CSI from LHexp and BLexp, the measure that also penalises the false alarms. As expected, these values are considerably lower than the POD (with maximum values around 0.6) because plume area and $\mathrm{SO}_{2}$ burden are 
overestimated in both experiments (see Fig. 9) leading to numerous false alarms. Both experiments behave similarly for the lower thresholds but $\mathrm{TCSO}_{2}$ values greater than $30 \mathrm{DU}$ are again captured better in LHexp.

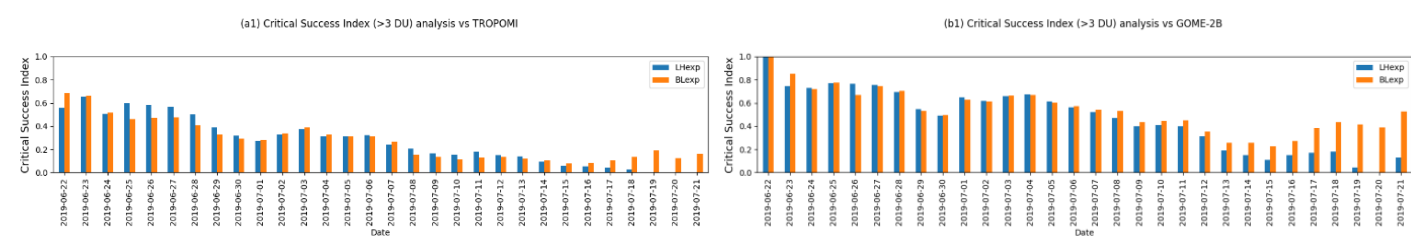

(a2) Cititica succs

(b2) Critical Success Index (>5 DU) analysis vs GOME-2B

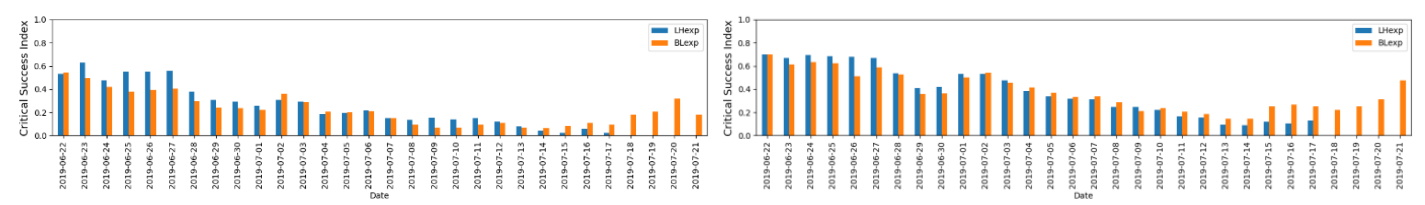

(a)) Critical Success Index (>10 DU) analysis vs TROPOMI
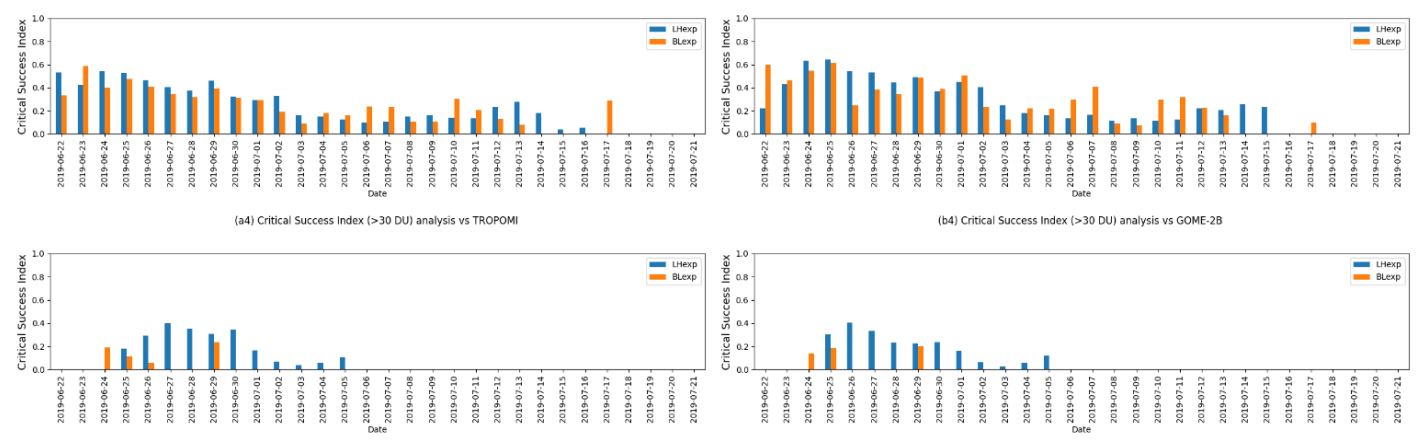

Figure 13: Timeseries of CSI for TCSO $_{2}$ analysis fields (at 0z) against (a) NRT TROPOMI and (b) GOME-2B for TCSO 2 thresholds of (1) 3DU, (2) 5 DU, (3) 10 DU and (4) 30 DU. Values for LHexp are shown in blue, values for BLexp in orange.

In summary, as far as the $\mathrm{TCSO}_{2}$ analysis fields are concerned the performance of LHexp and BLexp is similar for $\mathrm{TCSO}_{2}$ columns below $10 \mathrm{DU}$, but BLexp does not capture the higher $\mathrm{SO}_{2}$ values as well as LHexp. Both experiments overestimate the $\mathrm{SO}_{2}$ burden and the plume area compared to the TROPOMI NRT and GOME-2B observations.

\subsubsection{Vertical location of the $\mathrm{SO}_{2}$ plume}

While the $\mathrm{TCSO}_{2}$ analyses from LHexp and BLexp score similarly in the detection of the $\mathrm{TCSO}_{2}$ plume observations by GOME-2B and NRT TROPOMI, at least for values less than $10 \mathrm{DU}$, the vertical distributions of the $\mathrm{SO}_{2}$ plumes from the experiments differ considerably. Figure 14 shows vertical cross sections along $60^{\circ} \mathrm{N}$ between $120-300^{\circ} \mathrm{E}$ through the $\mathrm{SO}_{2}$ plume on 29 June 2019 from LHexp and BLexp. The figure illustrates that the bulk of the $\mathrm{SO}_{2}$ plume is located between 200-100 hPa in LHexp while it is located much lower, between 600-400 hPa, in BLexp. To assess which vertical distribution is more realistic, in Figure 15 we compare the plume heights from the experiments with $\mathrm{SO}_{2}$ altitudes derived from IASI LATMOS ULB data (Clarisse et al., 2012) for the period 22 to 29 June 2019. The CAMS plume altitude was calculated as the altitude where the highest $\mathrm{SO}_{2}$ value were found in the CAMS $\mathrm{SO}_{2}$ profiles. The figure shows that the plume height in LHexp agrees well with the independent IASI plume altitude with a mean bias of $0.4 \pm 2.2 \mathrm{~km}$, while BLexp underestimates the plume altitude with a mean bias of $-5.1 \pm 2.1 \mathrm{~km}$. Figure 15 illustrates that the altitude of the Raikoke $\mathrm{SO}_{2}$ plume in the CAMS analysis is considerably improved if $\mathrm{SO}_{2} \mathrm{LH}$ data are used than when using the baseline configuration. 
(a) LHexp, SO2 [ppb]

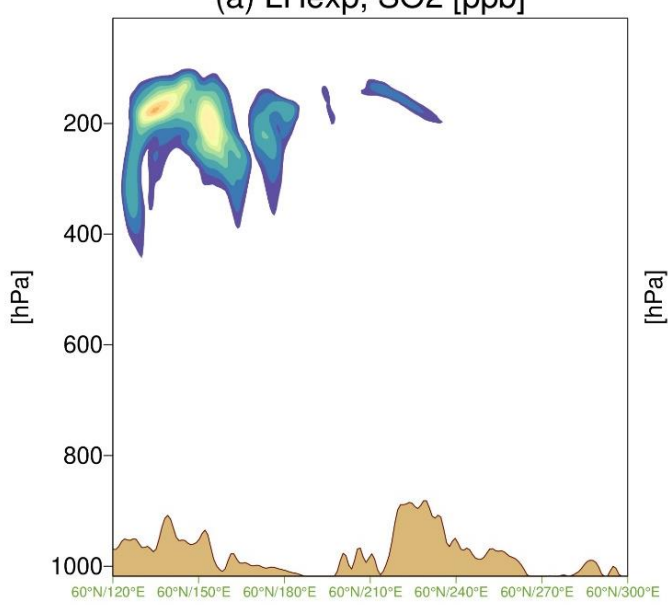

(b) BLexp, SO2 [ppb]

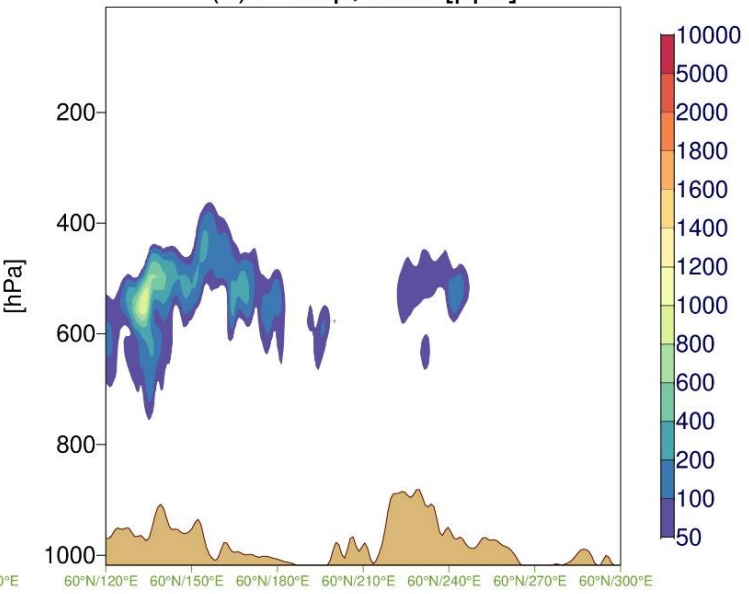

Figure 14: Vertical cross sections along $60^{\circ} \mathrm{N}$ between $120-300^{\circ} \mathrm{E}$ showing the $\mathrm{SO}_{2}$ analysis field (in ppb) from (a) $\mathrm{LHexp}$ and (b) BLexp on 29 June 2019, 0z.
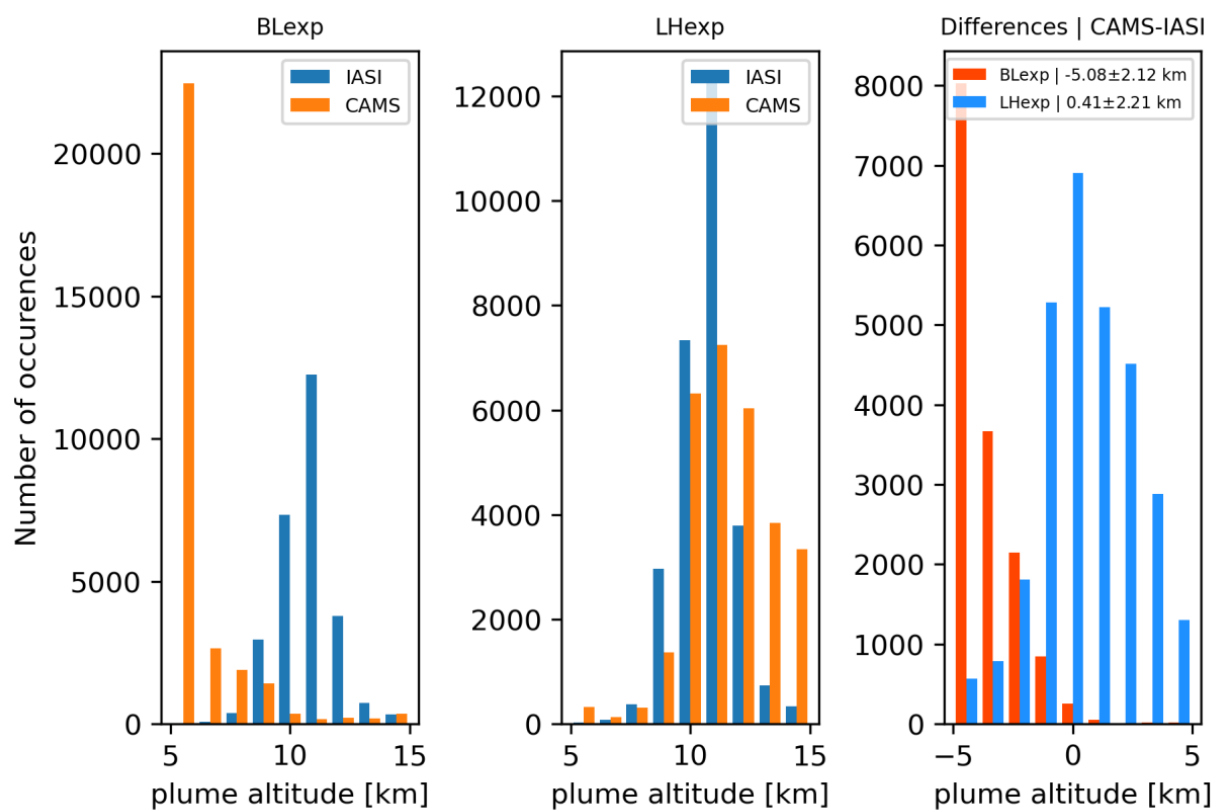

510

Figure 15: Comparison of plume altitude from IASI ULB LATMOS data with the altitude of maximum $\mathrm{SO}_{2}$ concentration from the LHexp (middle panel) and BLexp (left panel) for the period 22-29 June 2019. The right panel shows a histogram of the differences of the plume altitudes (CAMS minus IASI) for LHexp (blue) and BLexp (red).

\subsubsection{Quality of the 5-day $\mathrm{TCSO}_{2}$ forecasts}

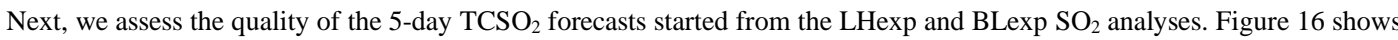
a timeseries of POD for a $\mathrm{TCSO}_{2}$ threshold of $5 \mathrm{DU}$ from LHexp and BLexp for NRT TROPOMI and GOME-2B for the initial $\mathrm{SO}_{2}$ analysis and forecasts valid on the same day at different lead-times (24 to 120 hours). The figure shows that the skill decreases with increasing forecast lead-time in both experiments, but that the degradation of skill with forecast lead- 

hour forecast still has values of 0.4. In contrast, BLexp only has POD values between 0.2 and 0.4 for the 72-hour forecasts
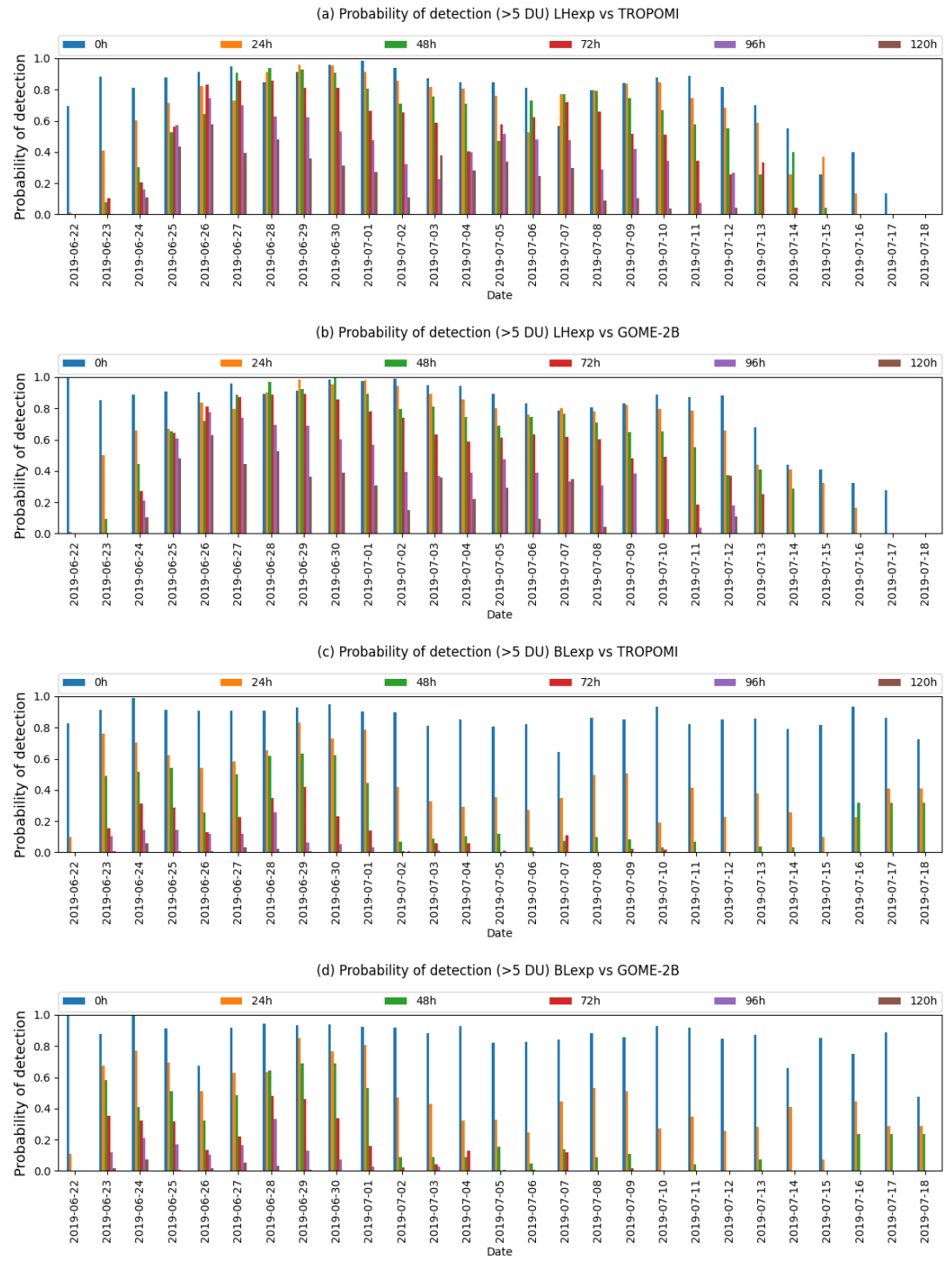

Figure 16: Probability of detection of LHexp against (a) NRT TROPOMI and (b) GOME-2B, as well as BLexp against (c) NRT TROPOMI and (d) GOME-2B for the period 22 June to 18 July 2021 for analysis at 0z (blue), 24-hour forecast (orange), 48-hour forecast (green), 72-hour forecast (red), 96-hour forecast (purple) and 120-hour forecast (brown).

during June while values drop considerably during July when even the short 24-hour forecasts from BLexp only have POD values between 0.2 and 0.4. In other words, in BLexp the skill of forecasting the location of the $\mathrm{SO}_{2}$ plumes seen by GOME2B and the NRT TROPOMI one day in advance is similar to the skill of forecasting the $\mathrm{SO}_{2}$ plumes 4 days in advance in LHexp. The main reason for the lower forecast quality in BLexp is the fact that the $\mathrm{SO}_{2}$ plumes are located at the wrong altitude (see Fig. 15) so that the prevailing winds will not transport the $\mathrm{SO}_{2}$ in the correct direction.

To further assess the forecast skill, we use the fractional skill score (FSS) which is a spatial comparison. It was originally used to assess the quality of precipitation forecasts (Roberts and Lean, 2007) but has more recently also been used to assess 
the skill of dispersion models to capture volcanic plumes (de Leeuw et al, 2020; Dacre et al., 2016; Harvey and Dacre, 2016). The FSS is calculated using the ratio of the modelled and observed fractional coverage of the $\mathrm{SO}_{2}$ plume at each location for various horizontal scales (neighbourhoods) and thresholds, and it assesses how the skill of the forecast varies depending on those parameters. To calculate it we grid the model $\mathrm{TCSO}_{2}$ analyses and forecasts at various lead-times and the NRT TROPOMI and GOME-2B TCSO${ }_{2}$ observations on a $1^{\circ} \times 1^{\circ}$ grid and create binary fields for the chosen thresholds (in our case for $\mathrm{TCSO}_{2}>1,3,5,10,20,30,50 \mathrm{DU}$ ). Then, for each grid point, the fraction of surrounding grid points that exceed the threshold is calculated from the model field and the observations. To establish at which horizontal scale the $\mathrm{SO}_{2}$ analysis or forecast is useful we repeat this exercise with neighbourhoods of varying scales (i.e. $1,3,5^{\circ}$, corresponding to neighbourhoods of 1,9 and 25 grid boxes, respectively). An FSS of 1 means perfect alignment of the features in the observations and the model and an FSS of 0 a total mismatch. We use values of FSS greater than 0.5 to define a simulation that has some skill. This value was also used by de Leeuw et al. (2020) and Harvey and Dacre (2016). The FSS for a neighbourhood of length $\mathrm{n}$ is calculated following Roberts and Lean (2007) as

$$
F S S_{(n)}=1-\frac{M S E_{(n)}}{M S E_{(n) r e f}}
$$

550

where MSE is the Mean Square Error and $\operatorname{MSE}_{(\mathrm{n})}=0$ for a perfect forecast of neighbourhood with length $\mathrm{n}$. The reference MSE for each neighbourhood length $\mathrm{n}$ is given by:

$$
M S E_{(n) r e f}=\frac{1}{N_{x} N_{y}}\left[\sum_{i-1}^{N_{x}} \sum_{j-1}^{N_{y}} O_{(n) i, j}^{2}+\sum_{i-1}^{N_{x}} \sum_{j-1}^{N_{y}} M_{(n) i, j}^{2}\right]
$$

Here $i=1, N_{x}$ with $N_{x}$ the number of columns in the domain and $j=1, N_{y}$ with $N_{y}$ the number of rows. $M_{(n) i j, j}$ is the field of model fractions obtained from the model binary field for a square of length $n$ and $\mathrm{O}_{(\mathrm{n}) \mathrm{i}, \mathrm{j}}$ the corresponding field of observed fractions. $\operatorname{MSE}_{(\mathrm{n}) \mathrm{ref}}$ can be interpreted as the largest possible MSE that can be obtained from the model and observed fractions.
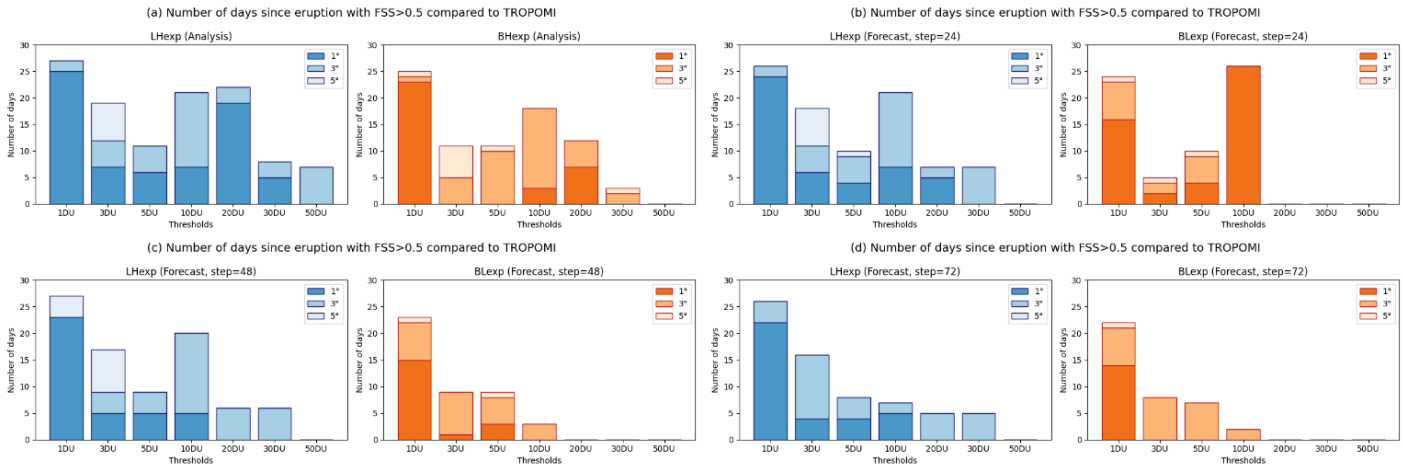

(e) Number of days
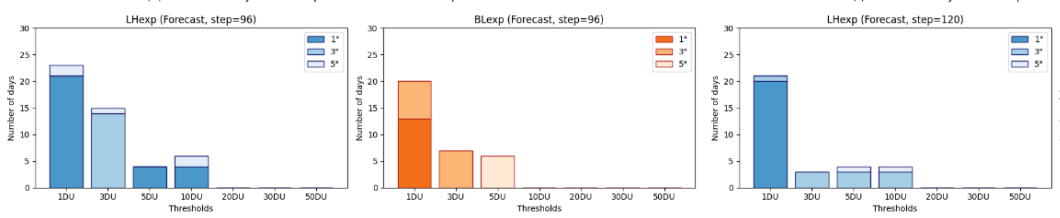

BLexp (forceast, step=120)

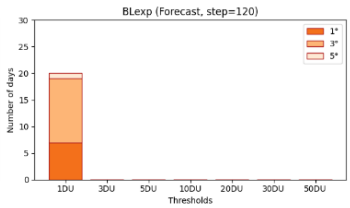

Figure 17: Number of days since the eruption on 22 June 2019 that the LHexp (blue) and BLexp (orange) (a) analyses and forecasts at steps (b) 24, (c) 48, (d) 72, (e) 96 and (f) 120-hours have some skill (FSS >0.5) compared to NRT TROPOMI TCSO data for neighbourhood sizes of $1^{\circ}, 3^{\circ}$ and $5^{\circ}$ and thresholds of $1,3,5,10,20,30,50 \mathrm{DU}$.

Figure 17 shows the number of days after the eruption that have FSS $>0.5$ when comparing LHexp and BLexp with NRT

TROPOMI data for the various thresholds, to give some indication of a skill timescale, i.e. how long the analyses and the forecasts started from them can be considered as useful after the initial eruption. Also shown (in the lighter shadings) are the additional useful forecast days that are gained when the neighbourhood size is increased to $3^{\circ}$ or $5^{\circ}$. The main findings of the 
figure are (1) the skill timescale is longer for the smaller thresholds, i.e. the overall shape of the plume is easier to reproduce than smaller scale filaments with higher $\mathrm{TCSO}_{2}$ values, (2) the skill timescale drops with lead-time, (3) the skill timescale increases if the neighbourhood size is increased, with a larger increase for higher thresholds, pointing to errors in the location of structures with higher $\mathrm{TCSO}_{2}$, which are reduced with a larger grid, and (4) that the skill timescale is greater in LHexp than in BLexp, leading to better forecasts of the plume longer in advance, as already seen in Fig. 16.

We now look at the individual panels in more detail. Figure 17a shows the skill timescales of the $\mathrm{TCSO}_{2}$ analyses from $\mathrm{TCSO}_{2}$ fields (especially for the lower thresholds), but that the number of useful days is slightly larger in LHexp and that BLexp fails to capture the highest $\mathrm{TCSO}_{2}$ values. It is interesting to see the large number of days with FSS $>0.5$ for the threshold of $20 \mathrm{DU}$ in LHexp, because this is the value below which no $\mathrm{TCSO}_{2}$ data are assimilated in LHexp. Figure 17b shows that the 24-hour forecasts in LHexp have similar skill to the analysis, which a skill timescale of 24 days for the $1 \mathrm{DU}$ threshold and a neighbourhood size of $1^{\circ}$, illustrating that the 24-hour from the LHexp analysis can predict the overall location of the $\mathrm{SO}_{2}$ plume very well. For higher thresholds (> $30 \mathrm{DU}$ ) this drops to about 5 days after the eruption, and there is no skill for a threshold of 50 DU. The skill of the 48 and 72-hour forecasts (Fig. 17c and d) are similar to that of the 24hour one for the thresholds up to $10 \mathrm{DU}$, but at a neighbourhood size of $1^{\circ}$ the higher values (>20 DU) have no skill anymore. As there is still skill on a 5-day timescale for these forecasts for a neighbourhood size of $3^{\circ}$, this suggests that it is the location of the filaments with high $\mathrm{TCSO}_{2}$ values that is not correct rather than the forecast not maintaining any of the higher $\mathrm{TCSO}_{2}$ values. Even the 96 and 120-hour forecasts (Fig. 17e and f) in LHexp have a skill timescale of slightly more than 20 days for the $1 \mathrm{DU}$ threshold at $1^{\circ}$, but the skill drops markedly for the higher thresholds, and for the 120-hour forecasts skill is only found for thresholds up to $10 \mathrm{DU}$ at $3^{\circ}$ for up to 3 days after the eruption. Nevertheless, Fig. 17 shows that by assimilating $\mathrm{SO}_{2} \mathrm{LH}$ data the CAMS system can predict the overall location of the $\mathrm{SO}_{2}$ plume up to 5 days in advance for about 20 days after the initial eruption. This corresponds to the time when the $\mathrm{FP}_{-} \mathrm{ILMSO} \mathrm{LH}_{2}$ retrieval does not detect volcanic $\mathrm{SO}_{2}$ anymore (see Fig. 8).

Figure 17 shows that the BLexp analysis has skill timescales similar to LHexp, confirming what was already seen in Figures 12 and 13. Despite placing the $\mathrm{SO}_{2}$ cloud at the wrong altitude, the overall shape of the $\mathrm{SO}_{2}$ plume is still captured by the $\mathrm{SO}_{2}$ analysis. However, for higher thresholds the number of useful days after the eruption is smaller in BLexp and the forecast skill drops more steeply with forecast lead-time than in LHexp. There is no skill for the 24-hour forecast at $1^{\circ}$ for thresholds greater than $20 \mathrm{DU}$, and for the 48-hour forecasts the skill timescale for a $1 \mathrm{DU}$ threshold at $1^{\circ}$ is 15 days, compared to 23 days in LHexp. The skill timescale remains around 14 days in BLexp for the 72 and 96-hour forecasts for a 1 DU threshold at $1^{\circ}$ and then drops to 6 days at 120-hours. For the 72 to 120-hour forecasts there is no skill for the higher

600 thresholds for a neighbourhood size of $1^{\circ}$, pointing to a worse misplacement of the smaller scale features of the plume with higher $\mathrm{TCSO}_{2}$ values than in LHexp.

Figure 18 shows the skill timescale for LHexp and BLexp analyses and forecasts against GOME-2B data. For GOME-2B the number of useful forecast days are generally slightly lower, especially for a threshold of 1 DU which might just be an artefact because GOME-2B does not detect so many volcanic pixels with low values. For thresholds of 3-30 DU the GOME2 results for a neighbourhood size of $1^{\circ}$ or $3^{\circ}$ are very similar to the TROPOMI results for all the forecast ranges, with skill timescales of about 10 days for forecast lead times up to 72 hour and around 5 days for the 96 -hour forecasts. Again, the performance of BLexp is worse than of LHexp and for the 48-hour forecasts there is almost no skill in BLexp for the $1^{\circ}$ neighbourhoods. 
610
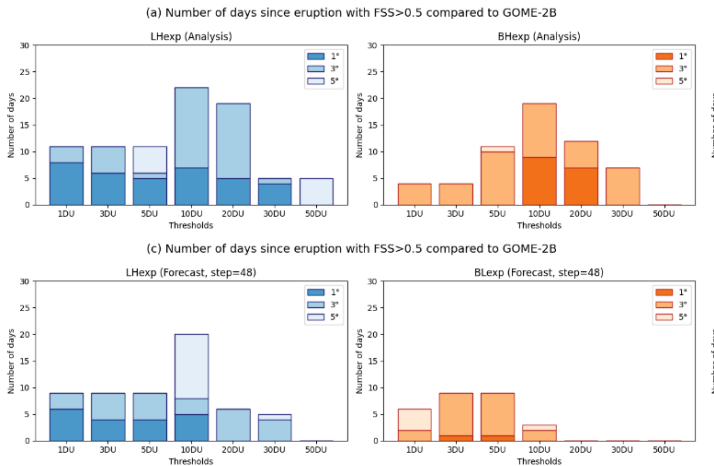

(e) Number of days
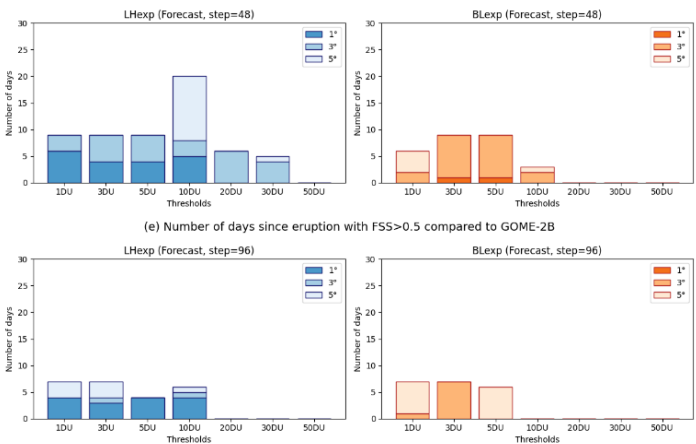

LHexp (Forecast, step- 72 )
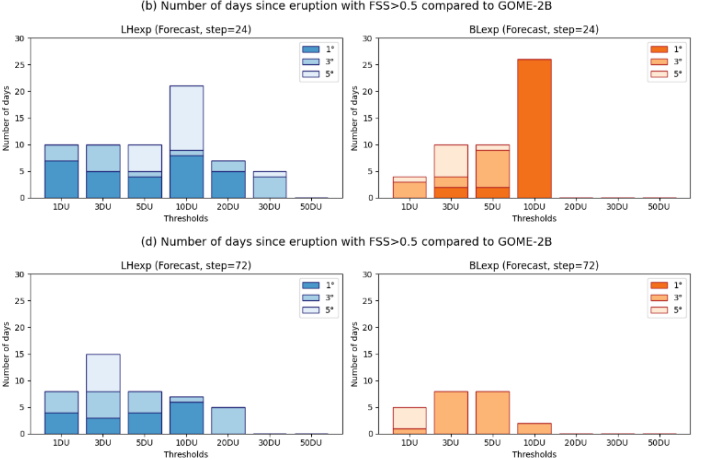

(f) Number of days since eruption with FSS $>0.5$ compared to GOME-2B
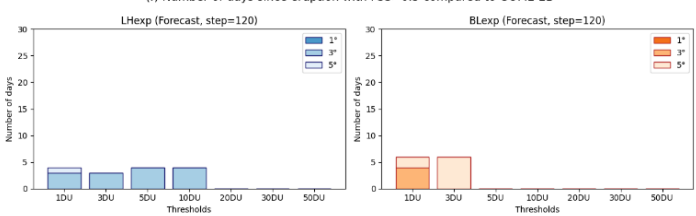

Figure 18: As Figure 17 but for GOME-2B TCSO . $_{2}$

\section{Conclusions}

615 In this paper we document the procedure used to assimilate near-real time $\mathrm{TCSO}_{2}$ retrievals from the TROPOMI and GOME-2 instruments in the operational CAMS NRT data assimilation system and explore the use of TROPOMI $\mathrm{SO}_{2}$ layer height data provided by the ESA-funded Sentinel-5P Innovation- $\mathrm{SO}_{2}$ Layer Height Project and produced with the FullPhysics Inverse Learning Machine algorithm (v3.1) developed by DLR. The assimilation of the FP_ILM SO 2 LH data was tested for the 2019 Raikoke eruption and compared with results obtained when assimilating NRT TROPOMI $\mathrm{TCSO}_{2}$ data with the operational CAMS configuration.

While the operational CAMS approach of placing the $\mathrm{SO}_{2}$ increment in the mid-troposphere around $550 \mathrm{hPa}$ gives surprisingly good results for the $\mathrm{TCSO}_{2}$ analyses and short-range forecasts in a lot of situation (including this case), the vertical distribution of $\mathrm{SO}_{2}$ in the baseline analysis is clearly wrong for the Raikoke eruption which injected a copious amount of $\mathrm{SO}_{2}$ into the stratosphere. By using the FP_ILM TROPOMI $\mathrm{SO}_{2} \mathrm{LH}$ data this can be much improved as comparison with the independent $\mathrm{SO}_{2}$ plume heights retrieved from IASI show. While the LH experiment agrees well with the IASI LATMOS ULB plume altitude retrievals, with a mean bias of $0.4 \pm 2.2 \mathrm{~km}$, the baseline experiment underestimates the plume altitude with a mean bias of $-5.1 \pm 2.1 \mathrm{~km}$. Consequently, the assimilation of the FP_ILM LH data leads to much improved $\mathrm{SO}_{2}$ forecasts and should improve the usefulness of the $\mathrm{CAMS} \mathrm{SO}_{2}$ forecasts for users and also for the aviation industry.

In the baseline experiment the forecast skill drops much more for longer forecast lead-times than in the LH experiment, which is seen when comparing point skill scores such as probability of detection and critical success index and when using the fractional skill score that also assesses spatial skill. Timeseries of the Probability of Detection score show that in the baseline experiment, the skill of forecasting the location of the Raikoke $\mathrm{SO}_{2}$ plume seen by GOME-2B and the NRT TROPOMI one day in advance is similar to the skill of forecasting the $\mathrm{SO}_{2}$ plume 4 days in advance in LHexp. The FSS shows that compared to NRT TROPOMI, even the 120-hour forecasts of the LH experiment have a significant skill up to 20 days after the initial eruption for the prediction of $\mathrm{TCSO}_{2}$ for a $1 \mathrm{DU}$ threshold and a neighbourhood size of $1^{\circ}$, suggesting that the overall location of the $\mathrm{SO}_{2}$ plume is well reproduced. The skill is smaller for higher $\mathrm{TCSO}_{2}$ thresholds (about 5 days 
640 for forecast ranges up to 96-hours on a $1^{\circ}$ grid), illustrating that it is more difficult to accurately predict the location of areas with higher $\mathrm{SO}_{2}$ columns which usually have smaller spatial scales. The skill timescale is shorter for the baseline experiment, with values around 15 days after the initial eruption for the 1 DU threshold for forecast ranges up to 96-hours and 5 days for the 120-hours forecasts, but there is no skill for any of the higher thresholds at a neighbourhood size of $1^{\circ}$ from 72 -hour forecasts onwards. By assimilating FP_ILM SO 2 LH data the CAMS system can predict the overall location of the Raikoke $\mathrm{SO}_{2}$ plume up to 5 days in advance for about 20 days after the initial eruption.

Our study also documents some issues of the CAMS $\mathrm{TCSO}_{2}$ assimilation approach, namely the overestimation of the $\mathrm{SO}_{2}$ burden and plume area by the data assimilation system, both in the operational configuration and when using the FP_ILM $\mathrm{SO}_{2} \mathrm{LH}$ data. The main reason for this overestimation is the coarse horizontal resolution used in the minimisations (currently TL95 and TL159 in the operational CAMS system) which limits the wavenumbers that can be resolved in the wavelet formulation of the $\mathrm{SO}_{2}$ background errors. This in turn limits the horizontal correlation length scale that can be used for the $\mathrm{SO}_{2}$ background errors and that determines how for the increments from individual observations are spread out in the horizontal. In this paper we used TL159/TL255 as the resolutions for the minimisations, but to properly resolve small scale structures the resolutions of the minimisations would have to be even higher. Obviously, this would increase the numerical cost of running the minimisation.

Other reasons that can contribute to an overestimation of the $\mathrm{SO}_{2}$ burden or plume area in the CAMS $\mathrm{SO}_{2}$ analysis could be the use of anthropogenic $\mathrm{SO}_{2}$ emissions in the CAMS model as the satellite data used for the comparisons are only the volcanic pixels. However, tests run without the anthropogenic emissions (not shown in this paper) did not show large differences compared to the experiments presented here, suggesting that this is not a big effect for the Raikoke eruption. Another possibility could be the fact that the satellite might miss a plume or part of a plume, but that the whole plume is present in the model. Finally, for the FP_ILM LH data the retrieval is limited to $\mathrm{TCSO}_{2}>20$ DU (in v3.1) and lower values that might correct an overestimation from the previous analysis cycle are not used. In future we hope to also test the assimilation of IASI $\mathrm{SO}_{2}$ retrievals with plume height information that would add extra information in the CAMS system.

One limitation in using the TROPOMI $\mathrm{SO}_{2} \mathrm{LH}$ data is that the version of the FP_ILM retrieval used in this study (v3.1) only produces reliable information for $\mathrm{TCSO}_{2}>20 \mathrm{DU}$ so that most of the smaller volcanic eruptions that happen on a more regular basis than big explosive eruptions would be missed if only the FP_ILM TROPOMI $\mathrm{SO}_{2}$ LH data were assimilated in the CAMS NRT system. Improvements to the FP_ILM retrieval algorithm are on-going so that it should be possible to lower this limit in the future.

\section{Code and Data availability}

The model data used in this paper are available from https://apps.ecmwf.int/research-experiments/expver/ using the following DOIs for the 6 experiments:

- hhu5: 10.21957/cygt-xf49

- hgze: 10.21957/qfam-7474

- hhbu: $10.21957 / z p d t-f 079$

- hhtm: 10.21957/jraa-s174

- hhtn: 10.21957/ddxs-2v95

- hgz7: 10.21957/81bh-7h58 


\section{Acknowledgements}

The Copernicus Atmosphere Monitoring Service is operated by the European Centre for Medium-Range Weather Forecasts on behalf of the European Commission as part of the Copernicus program (http://copernicus.eu) and CAMS data are freely available from atmosphere.copernicus.eu/data. The $\mathrm{SO}_{2}$ analysis and forecast experiments used in this paper are available from https://apps.ecmwf.int/research-experiments/expver/ (see DOIs in Table 3). The FP_ILM TROPOMI SO $\mathrm{LH}_{2}$ product was developed in the framework of the ESA Sentinel-5p Innovation project. MEK would like to acknowledge the Aristotle University of Thessaloniki (AUTh) High Performance Computing Infrastructure and Resources and the help of the AUTh IT Center. MEK further acknowledges the use of the Atmospheric Toolbox®. IASI is a joint mission of EUMETSAT and the Centre National d'Etudes Spatiales (CNES, France). The authors acknowledge the AERIS data infrastructure, https://en.aeris-data.fr/, for providing access to the IASI $\mathrm{SO}_{2}$ plume height data used in this study and ULB-LATMOS for the development of the retrieval algorithms. Thanks to Anabel Bowen for improving Figures 5 and 9.

\section{Author Contributions}

AI prepared the code to assimilate the $\mathrm{SO}_{2} \mathrm{LH}$ data, ran the analysis experiments, carried out most of the validation and wrote the paper. MA helped with the construction of the background error matrices. JF provided help with the modelling framework and RR wrote the converter software to transfer the $\mathrm{SO}_{2} \mathrm{LH}$ data from their native netcdf format to the BUFR format used in the ECMWF data assimilation system. MEK and DB performed the validation against the IASI/MetOp $\mathrm{SO}_{2}$ plume altitude data and provided Fig. 15. PH provided the $\mathrm{SO}_{2}$ LH data and developed the FP_ILM algorithm. DE and DL also contributed to the FP_ILM developments. All co-authors provided useful feedback on the paper.

\section{References}

Brenot, H., Theys, N., Clarisse, L., van Geffen, J., van Gent, J., Van Roozendael, M., van der A, R., Hurtmans, D., Coheur, P.-F., Clerbaux, C., Valks, P., Hedelt, P., Prata, F., Rasson, O., Sievers, K., and Zehner, C.: Support to Aviation Control Service (SACS): an online service for near-real-time satellite monitoring of volcanic plumes, Nat. Hazards Earth Syst. Sci., 14, 1099-1123, doi:10.5194/nhess-14-1099-2014, 2014.

Brenot, H., Theys, N., Clarisse, L., van Gent, J., Hurtmans, D. R., Vandenbussche, S., Papagiannopoulos, N., Mona, L., Virtanen, T., Uppstu, A., Sofiev, M., Bugliaro, L., Vázquez-Navarro, M., Hedelt, P., Parks, M. M., Barsotti, S., Coltelli, M., Moreland, W., Arnold-Arias, D., Hirtl, M., Peltonen, T., Lahtinen, J., Sievers, K., Lipok, F., Rüfenacht, R., Haefele, A., Hervo, M., Wagenaar, S., Som de Cerff, W., de Laat, J., Apituley, A., Stammes, P., Laffineur, Q., Delcloo, A., Lennart, R., Rokitansky, C.-H., Vargas, A., Kerschbaum, M., Resch, C., Zopp, R., Plu, M., Peuch, V.-H., Van Roozendael, M., and Wotawa, G.: EUNADICS early warning system dedicated to support aviation in case of crisis from natural airborne hazard and radionuclide cloud, Nat. Hazards Earth Syst. Sci. Discuss. [preprint], https://doi.org/10.5194/nhess-2021-105, in review, 2021.

Carn, S.A., Clarisse, L. and Prata, A.J.: Multi-decadal Satellite Measurements of Global Volcanic Degassing. Journal of Volcanology and Geothermal Research, 311, 99-134. doi:10.1016/j.jvolgeores.2016.01.002, 2016.

Clarisse, L., Hurtmans, D., Clerbaux, C., Hadji-Lazaro, J., Ngadi, Y., and Coheur, P.-F.: Retrieval of sulphur dioxide from the infrared atmospheric sounding interferometer (IASI), Atmos. Meas. Tech., 5, 581-594, https://doi.org/10.5194/amt-5581-2012, 2012. 
720 Clarisse, L., Coheur, P.-F., Theys, N., Hurtmans, D., and Clerbaux, C.: The 2011 Nabro eruption, a SO $\mathrm{S}_{2}$ plume height analysis using IASI measurements, Atmos. Chem. Phys., 14, 3095-3111, https://doi.org/10.5194/acp-14-3095-2014, 2014.

Clerbaux, C., Hadji-Lazaro, J., Turquety, S., et al., Tracking pollutants from space: Eight years of IASI satellite observation, Comptes Rendus Geoscience, Volume 347, Issue 3,Pages 134-144, https://doi.org/10.1016/j.crte.2015.06.001, 2015.

Courtier, P., Thépaut, J.-N., and Hollingsworth, A.: A strategy for operational implementation of 4D-Var, using an incremental approach, Q. J. Roy. Meteor. Soc., 120, 1367-1388, 1994.

Dacre, H. F., et al. (2011), Evaluating the structure and magnitude of the ash plume during the initial phase of the 2010 Eyjafjallajokull eruption using lidar observations and NAME simulations, J. Geophys. Res., 116, D00U03, doi:10.1029/2011JD015608.

de Leeuw, J., Schmidt, A., Witham, C. S., Theys, N., Taylor, I. A., Grainger, R. G., Pope, R. J., Haywood, J., Osborne, M., and Kristiansen, N. I.: The 2019 Raikoke volcanic eruption: Part 1 Dispersion model simulations and satellite retrievals of volcanic sulfur dioxide, Atmos. Chem. Phys. Discuss. [preprint], https://doi.org/10.5194/acp-2020-889, in review, 2020.

Harvey, N. J. and Dacre, H. F.: Spatial evaluation of volcanic ash forecasts using satellite observations, Atmos. Chem. Phys., 16, 861-872,https://doi.org/10.5194/acp-16-861-2016, 2016.

Efremenko, D. S., Loyola R., D. G., Hedelt, P., and Spurr, R. J. D.: Volcanic $\mathrm{SO}_{2}$ plume height retrieval from UV sensors using a full-physics inverse learning machine algorithm, Int. J. Remote Sens., 38, 1-27, https://doi.org/10.1080/01431161.2017.1348644, 2017.

Fedkin, N. M., Li, C., Krotkov, N. A., Hedelt, P., Loyola, D. G., Dickerson, R. R., and Spurr, R.: Volcanic $\mathrm{SO}_{2}$ effective layer height retrieval for the Ozone Monitoring Instrument (OMI) using a machine-learning approach, Atmos. Meas. Tech., 14, 3673-3691, https://doi.org/10.5194/amt-14-3673-2021, 2021.

Fisher, M. and Andersson, E.: Developments in 4D-Var and Kalman Filtering, ECMWF Technical Memorandum 347, available from ECMWF, Shinfield Park, Reading, Berkshire, RG2 9AX, UK,2001, https://www.ecmwf.int/sites/default/files/elibrary/2001/9409-developments-4d-var-and-kalman-filtering.pdf

Fisher, M.: Generalized frames on the sphere with application to background error covariance modelling, Seminar on resent developments in numerical methods for atmospheric and ocean modelling, 6-10 September 2004, Proceedings, ECMWF, pp.87-101, available from ECMWF, Shinfield Park, Reading, Berkshire, RG2 9AX, UK, 2004.

Fisher, M.: Wavelet $\mathrm{Jb}$ - A new way to model the statistics of back-ground errors, ECMWF Newsletter, 106, 23-28, available from ECMWF, Shinfield Park, Reading, Berkshire, RG2 9AX, UK,2006.

Flemming, J., and Inness, A. (2013), Volcanic sulfur dioxide plume forecasts based on UV satellite retrievals for the 2011 Grímsvötn and the 2010 Eyjafjallajökull eruption, J. Geophys. Res. Atmos., 118, 10,172-10,189, doi:10.1002/jgrd.50753. 
Flemming, J., Huijnen, V., Arteta, J., Bechtold, P., Beljaars, A., Blechschmidt, A.-M., Diamantakis, M., Engelen, R. J., Gaudel, A., Inness, A., Jones, L., Josse, B., Katragkou, E., Marecal, V., Peuch, V.-H., Richter, A., Schultz, M. G., Stein, O., and Tsikerdekis, A.: Tropospheric chemistry in the Integrated Forecasting System of ECMWF, Geosci. Model Dev., 8, 9751003, https://doi.org/10.5194/gmd-8-975-2015, 2015.

Flemming, J., Benedetti, A., Inness, A., Engelen, R. J., Jones, L., Huijnen, V., Remy, S., Parrington, M., Suttie, M., Bozzo, A., Peuch, V.-H., Akritidis, D., and Katragkou, E.: The CAMS interim Reanalysis of Carbon Monoxide, Ozone and Aerosol for 2003-2015, Atmos. Chem. Phys., 17, 1945-1983, https://doi.org/10.5194/acp-17-1945-2017, 2017

Goitom, B., Oppenheimer, C., Hammond, J. O. S., Grandin, R., Barnie, T., Donovan, A., Ogubazghi, G., Yohannes, E., Kibrom, G., Kendall,J.-M., et al.: First recorded eruption of Nabro volcano, Eritrea, 2011, B. Volcanol., 77, 85, https://doi.org/10.1007/s00445-015-0966-3,2015

Granier, C., S. Darras, H. Denier van der Gon, J. Doubalova, N. Elguindi, B. Galle, M. Gauss, M. Guevara, J.-P. Jalkanen, J. Kuenen, C. Liousse, B. Quack, D. Simpson, K. Sindelarova, The Copernicus Atmosphere Monitoring Service global and regional emissions (April 2019 version), Copernicus Atmosphere Monitoring Service (CAMS) report, 2019, doi:10.24380/d0bn-kx16.

Grebennikov, V.S., Zubachev, D.S., Korshunov, V.A. et al. Observations of Stratospheric Aerosol at Rosgidromet Lidar Stations after the Eruption of the Raikoke Volcano in June 2019. Atmos Ocean Opt 33, 519-523 (2020). https://doi.org/10.1134/S1024856020050097

Hedelt, P., Efremenko, D. S., Loyola, D. G., Spurr, R., and Clarisse, L.: Sulfur dioxide layer height retrieval from Sentinel-5 Precursor/TROPOMI using FP_ILM, Atmos. Meas. Tech., 12, 5503-5517, https://doi.org/10.5194/amt-12-5503-2019, 2019.

Huijnen, V., Williams, J., van Weele, M., van Noije, T., Krol, M., Dentener, F., Segers, A., Houweling, S., Peters, W., de Laat, J., Boersma, F., Bergamaschi, P., van Velthoven, P., Le Sager, P., Eskes, H., Alkemade, F., Scheele, R., Nédélec, P., and Pätz, H.-W.: The global chemistry transport model TM5: description and evaluation of the tropospheric chemistry version 3.0, Geosci. Model Dev., 3, 445-473, https://doi.org/10.5194/gmd-3-445-2010, 2010.

Inness, A., Blechschmidt, A.-M., Bouarar, I., Chabrillat, S., Crepulja, M., Engelen, R. J., Eskes, H., Flemming, J., Gaudel, A., Hendrick, F., Huijnen, V., Jones, L., Kapsomenakis, J., Katragkou, E., Keppens, A., Langerock, B., de Mazière, M., Melas, D., Parrington, M., Peuch, V. H., Razinger, M., Richter, A., Schultz, M. G., Suttie, M., Thouret, V., Vrekoussis, M., Wagner, A., and Zerefos, C.: Data assimilation of satellite-retrieved ozone, carbon monoxide and nitrogen dioxide with ECMWF's Composition-IFS, Atmos. Chem. Phys., 15, 5275-5303, https://doi.org/10.5194/acp-15-5275-2015, 2015.

Inness, A., Ades, M., Agustí-Panareda, A., Barré, J., Benedictow, A., Blechschmidt, A.-M., Dominguez, J. J., Engelen, R., Eskes, H., Flemming, J., Huijnen, V., Jones, L., Kipling, Z., Massart, S., Parrington, M., Peuch, V.-H., Razinger, M., Remy, S., Schulz, M., and Suttie, M.: The CAMS reanalysis of atmospheric composition, Atmos. Chem. Phys., 19, 3515-3556, https://doi.org/10.5194/acp-19-3515-2019, 2019.

Laloyaux P., Bonavita M., Chrust M., Gürol S. Exploring the potential and limitations of weak-constraint 4D-Var. Q J R Meteorol Soc. 2020;146:4067-4082.. org/10.1002/qj.3891 

Lambertian equivalent reflectivity (GE_LER) daily maps from UVN satellite measurements, Atmos. Meas. Tech., 13, 985999, https://doi.org/10.5194/amt-13-985-2020, 2020.

Moxnes, E. D., Kristiansen, N. I., Stohl, A., Clarisse, L., Durant, A., Weber, K., and Vogel, A. (2014), Separation of ash and sulfur dioxide during the 2011 Grímsvötn eruption, J. Geophys. Res. Atmos., 119, 7477- 7501, doi:10.1002/2013JD021129.

Munro, R., Lang, R., Klaes, D., Poli, G., Retscher, C., Lindstrot, R., Huckle, R., Lacan, A., Grzegorski, M., Holdak, A., Kokhanovsky, A., Livschitz, J., and Eisinger, M.: The GOME-2 instrument on the Metop series of satellites: instrument design, calibration, and level 1 data processing - an overview, Atmos. Meas. Tech., 9, 1279-1301, https://doi.org/10.5194/amt-9-1279-2016, 2016.

Muser, L. O., Hoshyaripour, G. A., Bruckert, J., Horváth, Á., Malinina, E., Wallis, S., Prata, F. J., Rozanov, A., von Savigny, C., Vogel, H., and Vogel, B.: Particle aging and aerosol-radiation interaction affect volcanic plume dispersion: evidence from the Raikoke 2019 eruption, Atmos. Chem. Phys., 20, 15015-15036, https://doi.org/10.5194/acp-20-15015-2020, 2020.

Nurmi (2003): Recommendations on the verification of local weather forecasts. ECMWF Techical Memorandum, no. 430, https://www.ecmwf.int/node/11401

Parrish, D. F. and Derber, J. C.: The National Meteorological Center's spectral statistical-interpolation analysis scheme, Mon. Weather Rev., 120, 1747-1763, 1992.

Platt, U. and Stutz, J.: Differential Optical Absorption Spectroscopy (DOAS): Principle and Applications, Springer, Berlin, 2008

Platt, U. (2017). Air Monitoring by Differential Optical Absorption Spectroscopy. In Encyclopedia of Analytical Chemistry, R.A. Meyers (Ed.). https://doi.org/10.1002/9780470027318.a0706.pub2

Prata, F., Woodhouse, M., Huppert, H. E., Prata, A., Thordarson, T., and Carn, S.: Atmospheric processes affecting the separation of volcanic ash and $\mathrm{SO}_{2}$ in volcanic eruptions: inferences from the May 2011 Grímsvötn eruption, Atmos. Chem. Phys., 17, 10709-10732, https://doi.org/10.5194/acp-17-10709-2017, 2017.

Rémy, S., Kipling, Z., Flemming, J., Boucher, O., Nabat, P., Michou, M., Bozzo, A., Ades, M., Huijnen, V., Benedetti, A., Engelen, R., Peuch, V.-H., and Morcrette, J.-J.: Description and evaluation of the tropospheric aerosol scheme in the European Centre for Medium-Range Weather Forecasts (ECMWF) Integrated Forecasting System (IFS-AER, cycle 45R1),

Geosci. Model Dev., 12, 4627-4659, https://doi.org/10.5194/gmd-12-4627-2019, 2019.

Rix, M., Valks, P., Hao, N., Loyola, D., Schlager, H., Huntrieser, H., Flemming, J., Koehler, U., Schumann, U., and Inness, A.: Volcanic $\mathrm{SO}_{2}, \mathrm{BrO}$ and plume height estimations using GOME-2 satellite measurements during the eruption of Eyjafjallajökull in May 2010, J. Geophys. Res.-Atmos., 117, D00U19, https://doi.org/10.1029/2011JD016718, 2012 
Schmidt, A., et al. (2014), Assessing hazards to aviation from sulfur dioxide emitted by explosive Icelandic eruptions, J. Geophys. Res. Atmos., 119, 14,180- 14,196, doi:10.1002/2014JD022070.

Stohl, A., Prata, A. J., Eckhardt, S., Clarisse, L., Durant, A., Henne, S., Kristiansen, N. I., Minikin, A., Schumann, U., Seibert, P., Stebel, K., Thomas, H. E., Thorsteinsson, T., Tørseth, K., and Weinzierl, B.: Determination of time- and heightresolved volcanic ash emissions and their use for quantitative ash dispersion modeling: the 2010 Eyjafjallajökull eruption, Atmos. Chem. Phys., 11, 4333-4351, https://doi.org/10.5194/acp-11-4333-2011, 2011.

Theys, N., Smedt, I. D., Yu, H., Danckaert, T., Gent, J. v., Hörmann, C., Wagner, T., Hedelt, P., Bauer, H., Romahn, F., et al.: Sulfur dioxide retrievals from TROPOMI onboard Sentinel-5 Precursor: algorithm theoretical basis., Atmos. Meas. Tech., 10, https://doi.org/10.5194/amt-10-119-2017, 2017.

Thomas, H. E., and A. J. Prata (2011), Sulphur dioxide as a volcanic ash proxy during the April-May 2010 eruption of Eyjafjallajökull Volcano, Iceland, Atmos. Chem. Phys., 11, 6871-6880, doi:10.5194/acp-11-6871-2011.

Tournigand, P.-Y., Cigala, V., Lasota, E., Hammouti, M., Clarisse, L., Brenot, H., Prata, F., Kirchengast, G., Steiner, A. K., and Biondi, R.: A multi-sensor satellite-based archive of the largest $\mathrm{SO}_{2}$ volcanic eruptions since 2006, Earth Syst. Sci. Data, 12, 3139-3159, https://doi.org/10.5194/essd-12-3139-2020, 2020.

865 Vaughan, G., Wareing, D., and Ricketts, H.: Measurement Report: Lidar measurements of stratospheric aerosol following the 2019 Raikoke and Ulawun volcanic eruptions, Atmos. Chem. Phys., 21, 5597-5604, https://doi.org/10.5194/acp-215597-2021, 2021.

Xu, J., Schüssler, O., Loyola R., D., Romahn, F., and Doicu, A.: A novel ozone profile shape retrieval using Full-Physics Inverse Learning Machine (FP-ILM)., IEEE J. Sel. Topics Appl. Earth Observ. Remote Sens., 10, 5442-5457, https://doi.org/10.1109/JSTARS.2017.2740168, 2017.

Yarwood, G., Rao, S., Yocke, M., and Whitten, G.: Updates to the carbon bond chemical mechanism: CB05, Final report to the US EPA, EPA Report Number: RT-0400675, available at: http://www.camx.com (last access: 18 May 2021), 2005. 